\title{
Solid-phase Synthesis of Oligonucleotide
}

\section{Glycoconjugates Bearing Three Different Glycosyl}

Groups: Orthogonally Protected Bis(hydroxymethyl)-

$N, N$ '-bis(3-hydroxypropyl)malondiamide

Phosphoramidite as the Key Building Block

Johanna Katajisto, * Petri Heinonen and Harri Lönnberg

Department of Chemistry, University of Turku, FIN-20014 Turku, Finland

\section{Supporting Information}

Table of Contents

Table of Contents

General

High-Performance Liquid Chromatography (HPLC)

Synthesis of $\mathbf{1 4}$

Synthesis of $\mathbf{1 7}$

Synthesis of $\mathbf{2 0}$

Synthesis of $\mathbf{1 5}$

Synthesis of $\mathbf{1 8}$ 
Figure S1. ${ }^{13} \mathrm{C}$ NMR spectrum of compound 4

Figure $\mathrm{S} 2 .{ }^{13} \mathrm{C}$ NMR spectrum of compound $\mathbf{5}$ S6

$\begin{array}{ll}\text { Figure S3. }{ }^{13} \mathrm{C} \text { NMR spectrum of compound } 6 & \text { S7 }\end{array}$

$\begin{array}{ll}\text { Figure S4. }{ }^{1} \mathrm{H} \text { NMR spectrum of compound } 7 & \text { S7 }\end{array}$

$\begin{array}{ll}\text { Figure S5. }{ }^{1} \mathrm{H} \text { NMR spectrum of compound } 8 & \text { S8 }\end{array}$

Figure S6. ${ }^{13} \mathrm{C}$ NMR spectrum of compound $9 \quad$ S8

Figure S7. ${ }^{13} \mathrm{C}$ NMR spectrum of compound $1 \quad$ S9

Figure S8. ${ }^{31} \mathrm{P}$ NMR spectrum of compound $\mathbf{1} \quad$ S9

$\begin{array}{ll}\text { Figure S9. }{ }^{13} \mathrm{C} \text { NMR spectrum of compound } \mathbf{1 3} & \text { S10 }\end{array}$

$\begin{array}{ll}\text { Figure S10. }{ }^{1} \mathrm{H} \text { NMR spectrum of compound } \mathbf{1 4} & \text { S10 }\end{array}$

Figure S11. ${ }^{1} \mathrm{H}$ NMR spectrum of compound $\mathbf{1 5} \quad$ S11

Figure S12. ${ }^{13} \mathrm{C}$ NMR spectrum of compound $\mathbf{1 6} . \quad$ S11

$\begin{array}{ll}\text { Figure S13. }{ }^{1} \mathrm{H} \text { NMR spectrum of compound } \mathbf{1 7} & \text { S12 }\end{array}$

$\begin{array}{ll}\text { Figure S14. }{ }^{13} \mathrm{C} \text { NMR spectrum of compound } \mathbf{1 8} & \text { S12 }\end{array}$

$\begin{array}{ll}\text { Figure S15. }{ }^{1} \mathrm{H} \text { NMR spectrum of compound } 19 & \text { S13 }\end{array}$

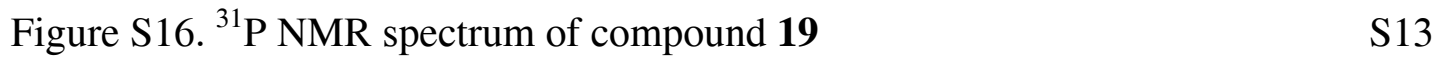

$\begin{array}{lr}\text { Figure S17. }{ }^{1} \mathrm{H} \text { NMR spectrum of compound } 20 & \text { S14 }\end{array}$

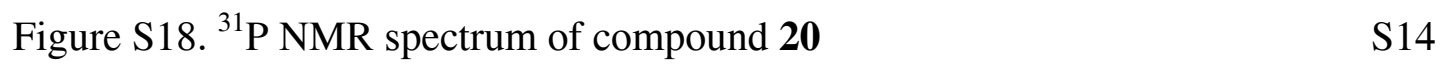

$\begin{array}{ll}\text { Figure S19. }{ }^{13} \mathrm{C} \text { NMR spectrum of compound } 21 & \text { S15 }\end{array}$

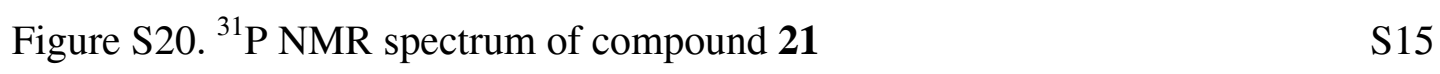

Figure S21. RP HPLC chromatogram of the crude product obtained from a sample of the solid-supported conjugate $\mathbf{2 4}$

S16

Figure S22. RP HPLC chromatogram of the crude product mixture obtained from a sample $\begin{array}{ll}\text { of the solid-supported conjugate } \mathbf{2 4} \text { after the TBDPS deprotection step } & \text { S17 }\end{array}$

$\begin{array}{ll}\text { Figure S23. RP HPLC chromatogram of purified } 25 & \text { S18 }\end{array}$

$\begin{array}{ll}\text { Figure S24. ESI-MS spectrum of compound } 25 & \text { S18 }\end{array}$

$\begin{array}{ll}\text { Figure S25. RP HPLC chromatogram of purified } 26 & \text { S19 }\end{array}$

$\begin{array}{ll}\text { Figure S26. ESI-MS spectrum of compound } 26 & \text { S19 }\end{array}$ 


\section{General}

The NMR spectra were recorded at 200, 400 or $500 \mathrm{MHz} .{ }^{1} \mathrm{H}$ NMR spectra were recorded, unless otherwise stated, in deuteriochloroform, and the chemical shifts are given in ppm from internal TMS. The coupling constants are reported in hertz. ${ }^{13} \mathrm{C}$ and ${ }^{31} \mathrm{P}$ NMR spectra were recorded, unless otherwise stated, in deuteriochloroform. The mass spectra were recorded by an ESI-MS or EI-MS methods.

THF and dioxane were distilled over $\mathrm{CaH}_{2}$ before use. DCM, MeCN and pyridine were dried over 4 Å molecular sieves. Triethylamine (TEA) was distilled from $\mathrm{CaH}_{2}$. Silica gel $60 \mathrm{~F}_{254}$ plates (Merck) were used for TLC, and dried Merck Silica gel (230-400 mesh) for column chromatography.

High-Performance Liquid Chromatography (HPLC). The oligonucleotide conjugates were analyzed and isolated on an analytical ThermoHypersil C-18 column $(4.6 \times 150 \mathrm{~mm}, 5 \mu \mathrm{m}$, a gradient elution from 0 to $100 \% \mathrm{~B}$ in $30 \mathrm{~min}$, flow rate $1 \mathrm{~mL} \mathrm{~min}^{-1}$, buffer $\mathrm{A}=0.05 \mathrm{~mol} \mathrm{~L}^{-1}$ $\mathrm{NH}_{4} \mathrm{OAc}$ (aq), buffer $\mathrm{B}=$ buffer $\mathrm{A}$ in $65 \% \mathrm{MeCN}$ ) and finally desalted. Eluent detection was monitored by UV absorbance at $260 \mathrm{~nm}$.

Methyl 6-O-trityl-2,3,4-tri- $O$-(p-toluoyl)- $\alpha$-D-mannopyranoside (14). Compound 14 was prepared as described for 13, using methyl $\alpha$-D-mannopyranoside (11) (5 g, $25.7 \mathrm{mmol})$ as a starting material. The compound $\mathbf{1 4}$ was obtained as a white solid foam in a $89 \%$ yield $(18.1 \mathrm{~g}) .{ }^{1} \mathrm{H}$ NMR $\left(\mathrm{CDCl}_{3}, 400 \mathrm{MHz}\right) \delta 8.05(\mathrm{~d}, 2 \mathrm{H}), 7.74(\mathrm{~d}, 2 \mathrm{H}), 7.65(\mathrm{~d}, 2 \mathrm{H}), 7.46(\mathrm{~d}, 4 \mathrm{H}), 7.29-7.33(\mathrm{~m}$, 5H), 7.06-7.20 (m, 12H), $5.97(\mathrm{t}, 1 \mathrm{H}, J=10.1 \mathrm{~Hz}), 5.76(\mathrm{dd}, 1 \mathrm{H}, J=3.4$ and $10.1 \mathrm{~Hz}), 5.66(\mathrm{dd}$, $1 \mathrm{H}, J=1.72$ and $3.3 \mathrm{~Hz}), 5.04(\mathrm{~d}, 1 \mathrm{H}, J=1.5 \mathrm{~Hz}), 4.12(\mathrm{~m}, 1 \mathrm{H}), 3.57(\mathrm{~s}, 3 \mathrm{H}), 3.41(\mathrm{dd}, 1 \mathrm{H}, J=2.3$ and $10.5 \mathrm{~Hz}), 3.35(\mathrm{dd}, 1 \mathrm{H}, J=5.1$ and $10.5 \mathrm{~Hz}), 2.46,2.38$ and 2.30 (each s, each $3 \mathrm{H}) ;{ }^{13} \mathrm{C}$ NMR $\left(\mathrm{CDCl}_{3}, 125 \mathrm{MHz}\right) \delta 165.7,165.6,165.2,146.9,143.8,130.0,129.8,129.7,129.3,128.9,128.7$, 
127.9, 127.3, 126.8, 105.9, 86.7, 70.6, 70.3, 66.9, 62.6, 55.2, 21.8, 21.6; Anal. Calcd for $\mathrm{C}_{50} \mathrm{H}_{46} \mathrm{O}_{9}$ : C, 75,93; H, 5.86, Found: C, 76.35; H, 5.71.

Methyl 2,3,4-tri- $O$-(p-toluoyl)- $\alpha$-D-mannopyranoside (17). Compound 17 was prepared as described for 16, using compound $14(18.1 \mathrm{~g}, 22.9 \mathrm{mmol})$ as a starting material. The product was obtained as a clear oil in a 95\% yield $(11.9 \mathrm{~g}){ }^{1} \mathrm{H} \mathrm{NMR}\left(\mathrm{CDCl}_{3}, 400 \mathrm{MHz}\right) \delta 7.87,7.72,7.28,7.18$ and 7.05 (each d, each 2H), $5.96(\mathrm{dd}, 1 \mathrm{H}, J=3.4$ and $10.1 \mathrm{~Hz}), 5.81(\mathrm{t}, 1 \mathrm{H}, J=10.1 \mathrm{~Hz}), 5.65(\mathrm{dd}$, $1 \mathrm{H}, J=1.6$ and $3.1 \mathrm{~Hz}), 5.00(\mathrm{~s}, 1 \mathrm{H}), 4.10(\mathrm{~m}, 1 \mathrm{H}), 3.80(\mathrm{~m}, 2 \mathrm{H}), 3.51(\mathrm{~s}, 3 \mathrm{H}), 2.44,2.36$ and 2.29 (each s, each $3 \mathrm{H}) ;{ }^{13} \mathrm{C} \mathrm{NMR}\left(\mathrm{CDCl}_{3}, 100 \mathrm{MHz}\right) \delta 166.7,165.6,165.5,144.5,143.9,129.9,129.8$, $129.3,129.2,129.0,99.8,70.9,70.4,69.4,67.2,55.4,31.6,22.7,21.8,21.7,21.6$; HRMS (EI) [MH] $]^{\top}$ calcd. 547.1977, obsd 547.1977.

\section{(Methyl 2,3,4-tri-O-(p-toluoyl)- $\alpha$-D-mannopyranoside-6-yl) methyl $N, N$ -}

diisopropylphosphoramidite (20). The phosphoramidite $\mathbf{2 0}$ was prepared as described for $\mathbf{1}$, using $17(200 \mathrm{mg}, 0.36 \mathrm{mmol})$ as a starting material. The product was obtained as a clear oil in a $74 \%$ yield (192 mg). ${ }^{1} \mathrm{H}$ NMR $\left(\mathrm{CDCl}_{3}, 500 \mathrm{MHz}\right) \delta 7.99,7.85,7.73,7.26,7.16$ and 7.05 (each d, each 2H), $5.84(\mathrm{~m} \mathrm{2H}), 5.62(\mathrm{~s}, 1 \mathrm{H}), 4.99(\mathrm{~d}, 1 \mathrm{H}, J=3.8 \mathrm{~Hz}), 4.25(\mathrm{~m}, 1 \mathrm{H}), 3.72-3.94(\mathrm{~m}, 2 \mathrm{H}), 3.55(\mathrm{~s}$, $3 \mathrm{H}), 3.53(\mathrm{~s}, 3 \mathrm{H}), 3.47(\mathrm{t}, 2 \mathrm{H}), 2.44,2.39$ and 2.28 (each s, each $3 \mathrm{H}), 1.12-1.16(\mathrm{~m}, 12 \mathrm{H}) ;{ }^{13} \mathrm{C}$ NMR $\left(\mathrm{CDCl}_{3}, 100 \mathrm{MHz}\right) \delta 165.7,165.5,144.0,143.7,130.0,129.8,129.2,129.1,128.9,70.6,70.2,67.1$, 63.1, 62.7, 55.2, 42.8, 24.7, 21.7, 21.6, 21.5; ${ }^{31} \mathrm{P} \mathrm{NMR}\left(\mathrm{CDCl}_{3}, 400 \mathrm{MHz}\right) \delta 149.8$.

Methyl 6- $O$-trityl-2,3,4-tri- $O$-(p-toluoyl)- $\alpha$-D-glucopyranoside (15). Compound 15 was prepared as described for 13, using methyl $\alpha$-D-glucopyranoside (12) (3 g, $15.4 \mathrm{mmol})$ as a starting material. The product was obtained as a white amorphous solid in $95 \%$ yield $(11.6 \mathrm{~g}) .{ }^{1} \mathrm{H}$ NMR $\left(\mathrm{CDCl}_{3}, 400 \mathrm{MHz}\right) \delta 7.95(\mathrm{~d}, 2 \mathrm{H}), 7.77(\mathrm{~d}, 2 \mathrm{H}), 7.64(\mathrm{~d}, 2 \mathrm{H}), 7.43(\mathrm{~d}, 4 \mathrm{H}), 7.08-7.33(\mathrm{~m}, 17 \mathrm{H})$, $6.07(\mathrm{t}, 1 \mathrm{H}, J=9.7 \mathrm{~Hz}), 5.51(\mathrm{t}, 1 \mathrm{H}, J=10.1 \mathrm{~Hz}), 5.28(\mathrm{~m}, 2 \mathrm{H}), 4.17(\mathrm{~m}, 1 \mathrm{H}), 3.54(\mathrm{~s}, 3 \mathrm{H}), 3.31(\mathrm{~m}$, 2H), 2.38, 2.37 and 2.29 (each s, each $3 \mathrm{H}) ;{ }^{13} \mathrm{C} \mathrm{NMR}\left(\mathrm{CDCl}_{3}, 100 \mathrm{MHz}\right) \delta 166.0,165.9,165.1$, $144.1,143.7,130.0,129.8,129.1,128.9,128.8,128.6,127.9,127.7,126.7,96.9,86.7,72.2,70.5$, 
69.5, 69.3, 62.7, 55.3, 21.7, 21.6; Anal. Calcd for $\mathrm{C}_{50} \mathrm{H}_{46} \mathrm{O}_{9}$ : C, 75,93; H, 5.86, Found: C, 75,86; H, 5.76 .

Methyl 2,3,4-tri- $O$-(p-toluoyl)- $\alpha$-D-glucopyranoside (18). Compound 18 was prepared as described for 16, using $15(11.6 \mathrm{~g}, 14.7 \mathrm{mmol})$ as a starting material. The product was obtained as a white amorphous solid in $74 \%$ yield $(6.00 \mathrm{~g}) .{ }^{1} \mathrm{H} \mathrm{NMR}\left(\mathrm{CDCl}_{3}, 400 \mathrm{MHz}\right) \delta 7.87(\mathrm{~d}, 2 \mathrm{H}), 7.78(\mathrm{~d}$, 2H), $7.18(\mathrm{t}, 4 \mathrm{H}), 6.98(\mathrm{~d}, 2 \mathrm{H}), 6.22(\mathrm{t}, 1 \mathrm{H}, J=10.8 \mathrm{~Hz}), 5.47(\mathrm{t}, 1 \mathrm{H}, J=10.0 \mathrm{~Hz}), 5.27(\mathrm{~m}, 2 \mathrm{H})$, $3.82(\mathrm{~m}, 1 \mathrm{H}), 3.80(\mathrm{~m}, 1 \mathrm{H}), 3.72(\mathrm{~m}, 1 \mathrm{H}), 3.39(\mathrm{~s}, 3 \mathrm{H}), 2.36,2.34$ and 2.28 (each s, each $3 \mathrm{H}) ;{ }^{13} \mathrm{C}$ $\operatorname{NMR}\left(\mathrm{CDCl}_{3}, 100 \mathrm{MHz}\right) \delta 169.6,165.9,165.8,144.6,144.1,143.8,130.1,129.9,129.7,129.2$, 129.1, 129.0, 97.2, 72.0, 69.8, 69.4, 61.1, 60.4, 55.6, 21.7, 21.6, 21.0; HRMS (EI) [M-H] calcd. 547.1977, obsd 547.1977.

(Methyl 2,3,4-tri- $O$-(p-toluoyl)- $\alpha$-D-glucopyranoside-6-yl) methyl $N, N$-diisopropylphosphoramidite (21). The phosphoramidite 21 was prepared as described for 1, using 18 (200 mg, 0.36 $\mathrm{mmol})$ as a starting material. The product was obtained as a clear oil in a $81 \%$ yield $(210 \mathrm{mg}) .{ }^{1} \mathrm{H}$ NMR $\left(\mathrm{CDCl}_{3}, 400 \mathrm{MHz}\right) \delta 7.86(\mathrm{~m}, 4 \mathrm{H}), 7.76,7.15$ and 7.06 (each d, each 2H), $6.13(\mathrm{~m}, 1 \mathrm{H}), 5.50$ (m, 1H), $5.23(\mathrm{~m}, 2 \mathrm{H}), 4.23(\mathrm{~m}, 1 \mathrm{H}), 3.36-3.91(\mathrm{~m}, 2 \mathrm{H}), 3.53-3.60(\mathrm{~m}, 2 \mathrm{H}), 3.47(\mathrm{~s}, 3 \mathrm{H}), 3.41,3.40$, 3.38 and 3.37 (four s, total $3 \mathrm{H}), 2.33,(\mathrm{~s}, 6 \mathrm{H}), 2.26(\mathrm{~s}, 3 \mathrm{H}), 1.34(\mathrm{~m}, 12 \mathrm{H}) ;{ }^{13} \mathrm{C} \mathrm{NMR}\left(\mathrm{CDCl}_{3}, 100\right.$ MHz) $\delta 165.9,165.8,165.4,163.4,144.0,143.6,130.0,129.9,129.7,129.0,128.9,96.8,72.1,70.4$, 69.8, 69.7, 69.6, 69.4, 62.9, 62.5, 55.4, 42.9, 24.7, 24.6, 21.6, 21.5; ${ }^{31} \mathrm{P}$ NMR $\left(\mathrm{CDCl}_{3}, 400 \mathrm{MHz}\right) \delta$ 149.2 . 


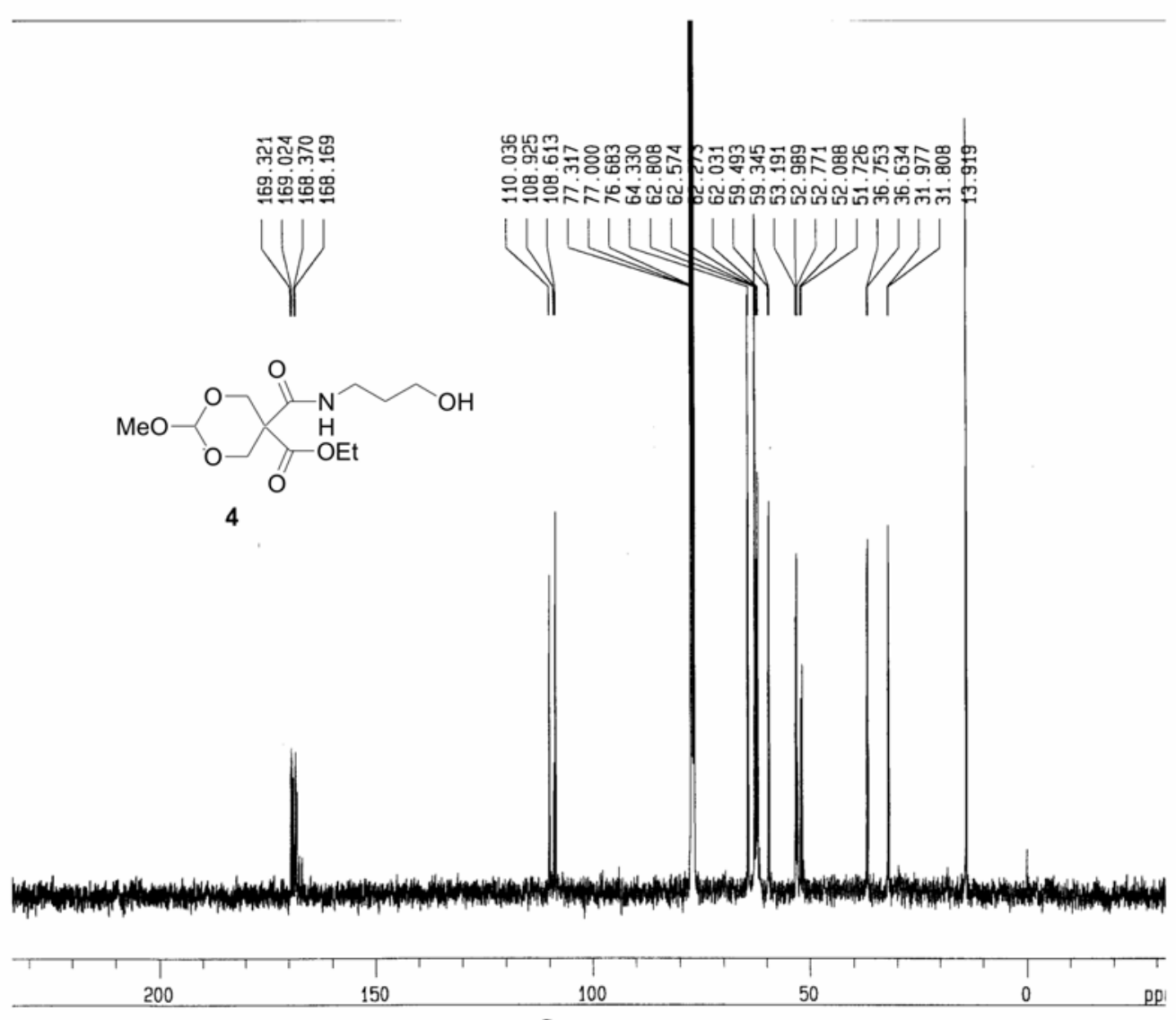

Figure S1. ${ }^{13} \mathrm{C}$ NMR spectrum of compound 4 .

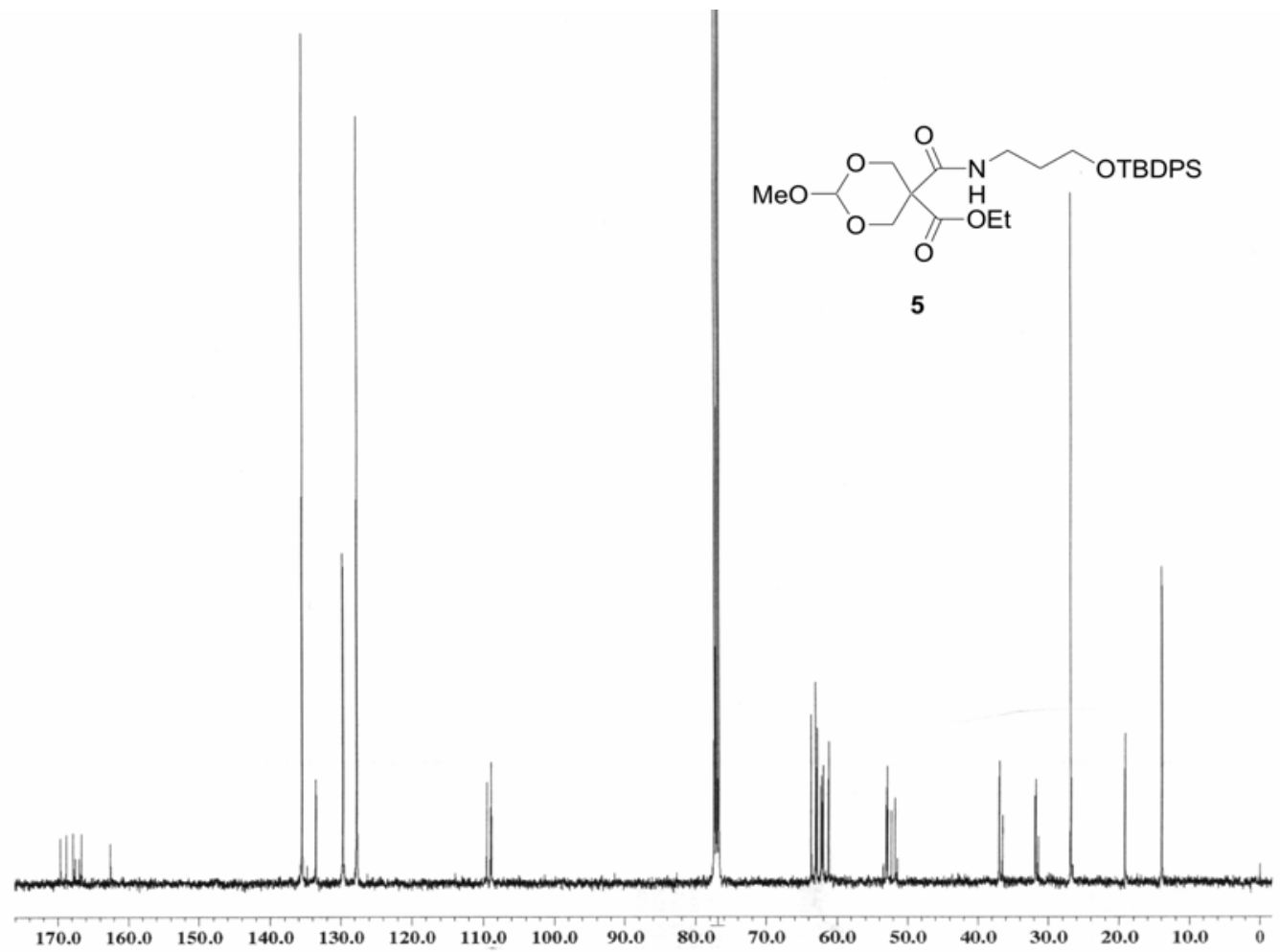

Figure S2. ${ }^{13} \mathrm{C}$ NMR spectrum of compound 5. 


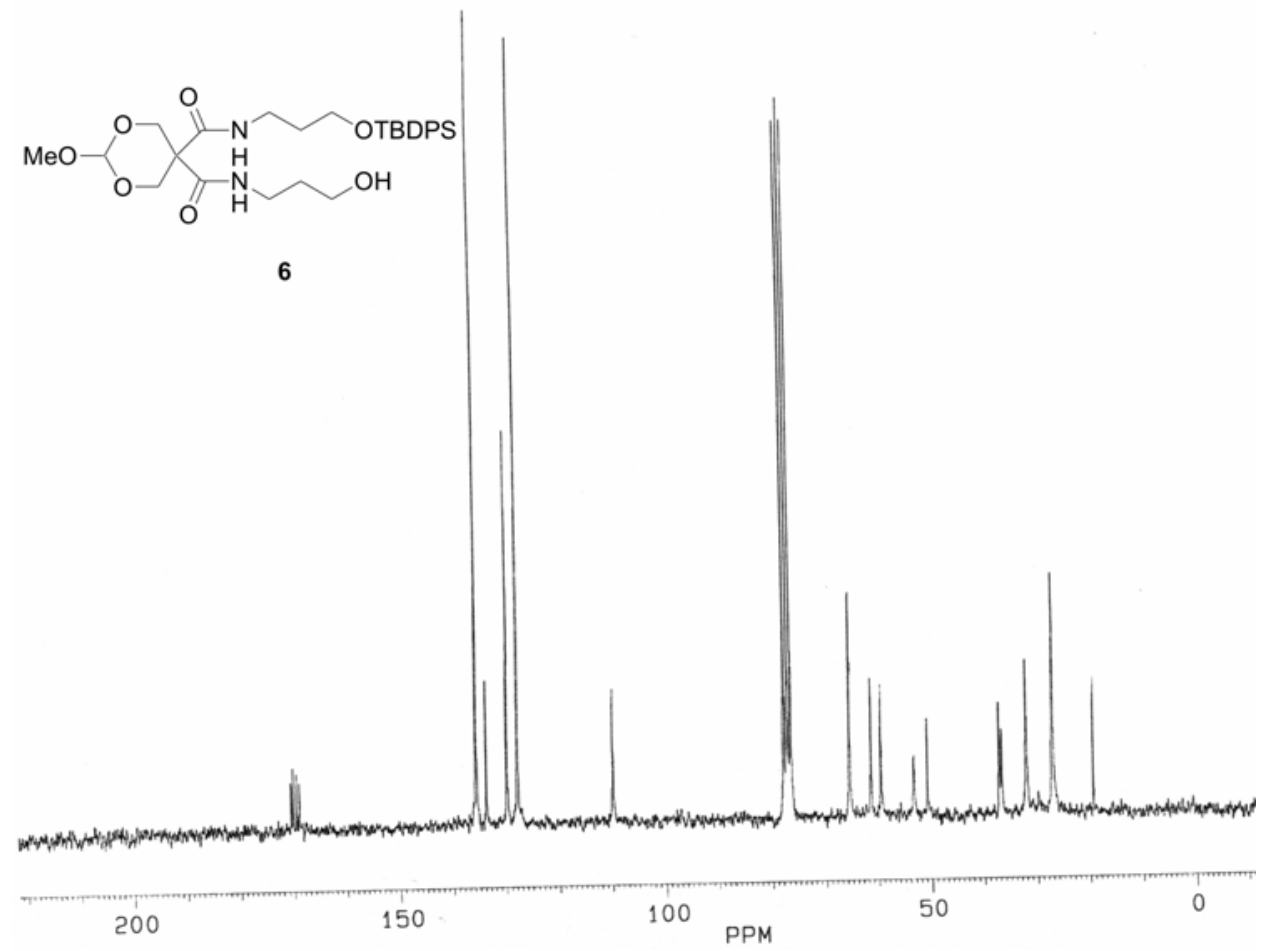

Figure S3. ${ }^{13} \mathrm{C}$ NMR spectrum of compound 6 .

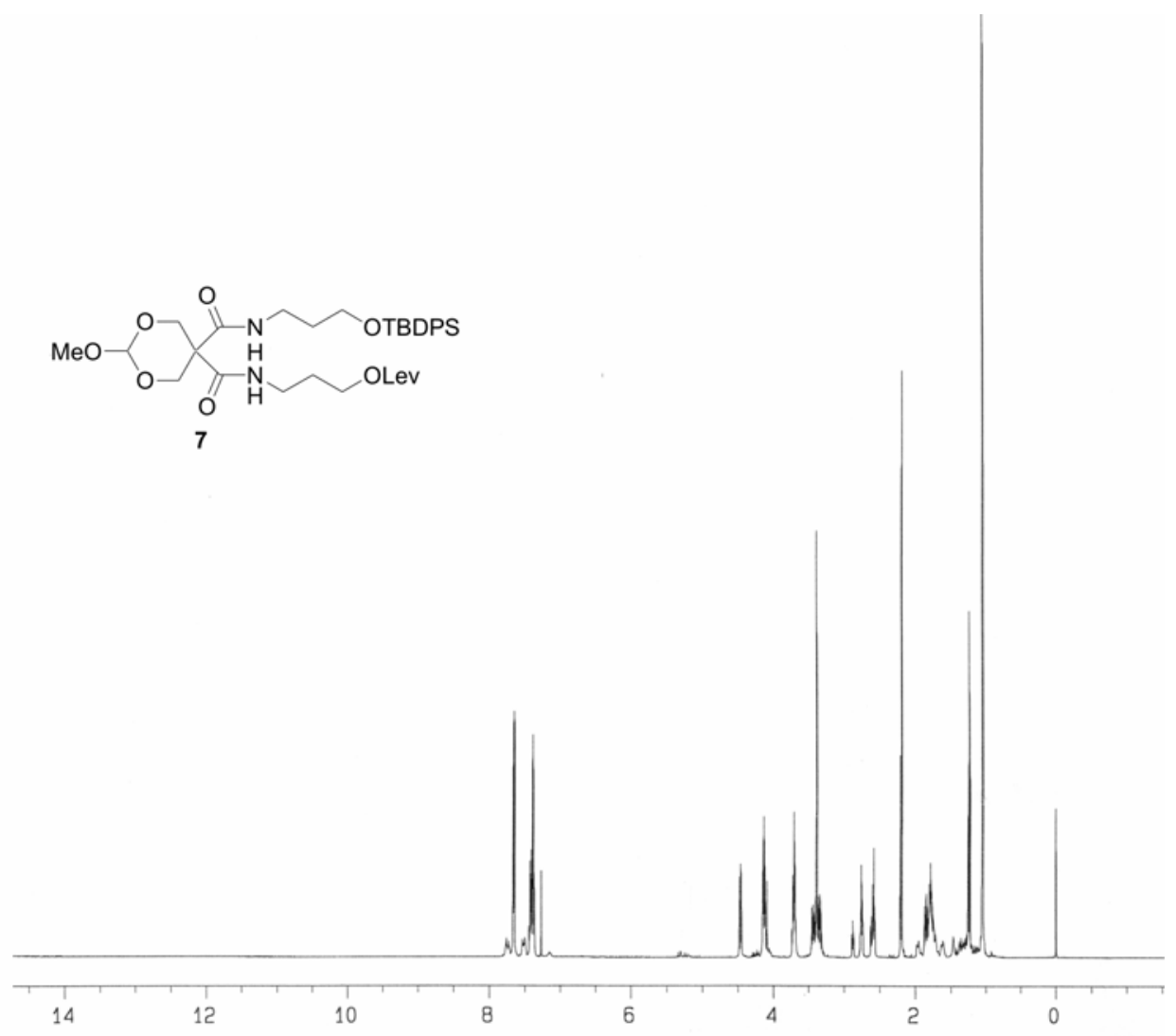

Figure S4. ${ }^{1} \mathrm{H}$ NMR spectrum of compound 7. 

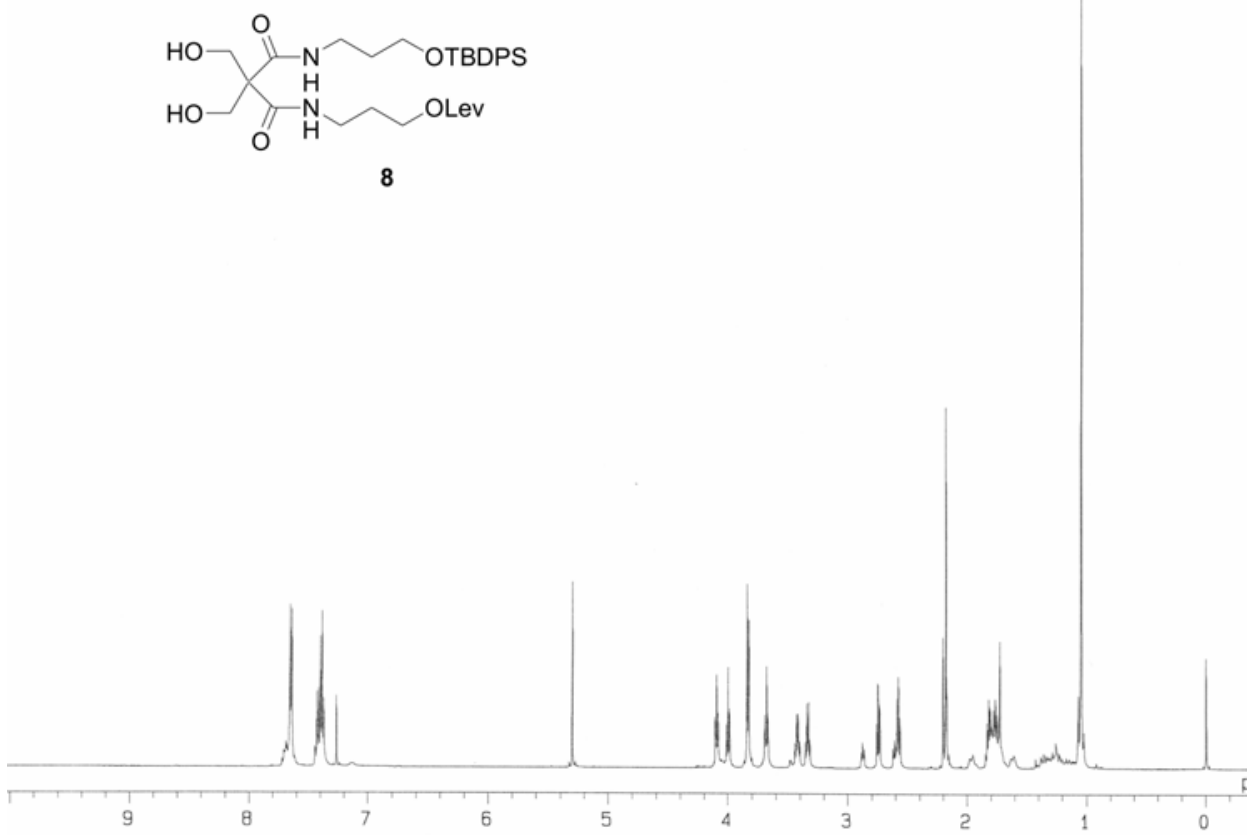

Figure S5. ${ }^{1} \mathrm{H}$ NMR spectrum of compound 8 .

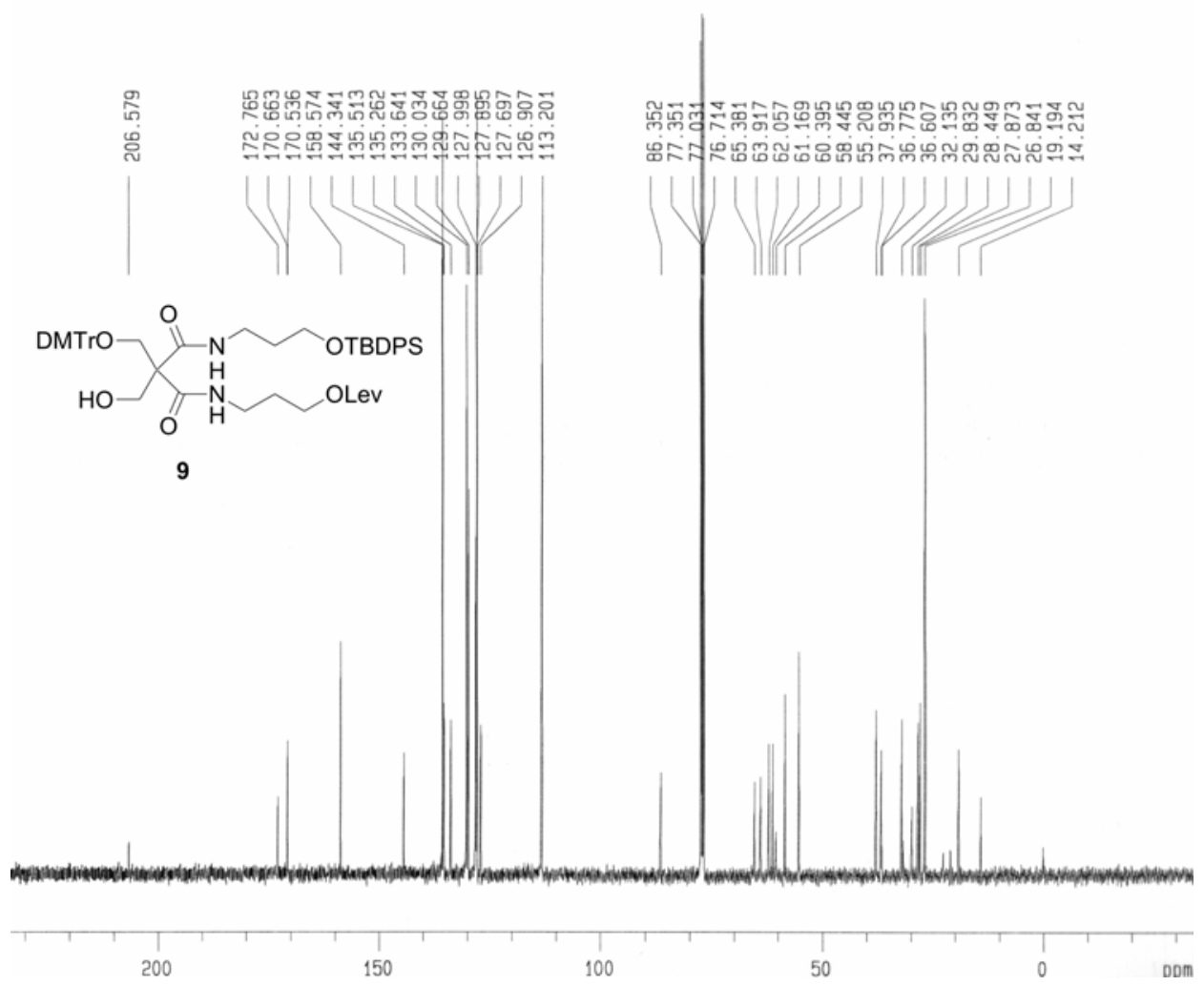

Figure S6. ${ }^{13} \mathrm{C}$ NMR spectrum of compound 9 . 


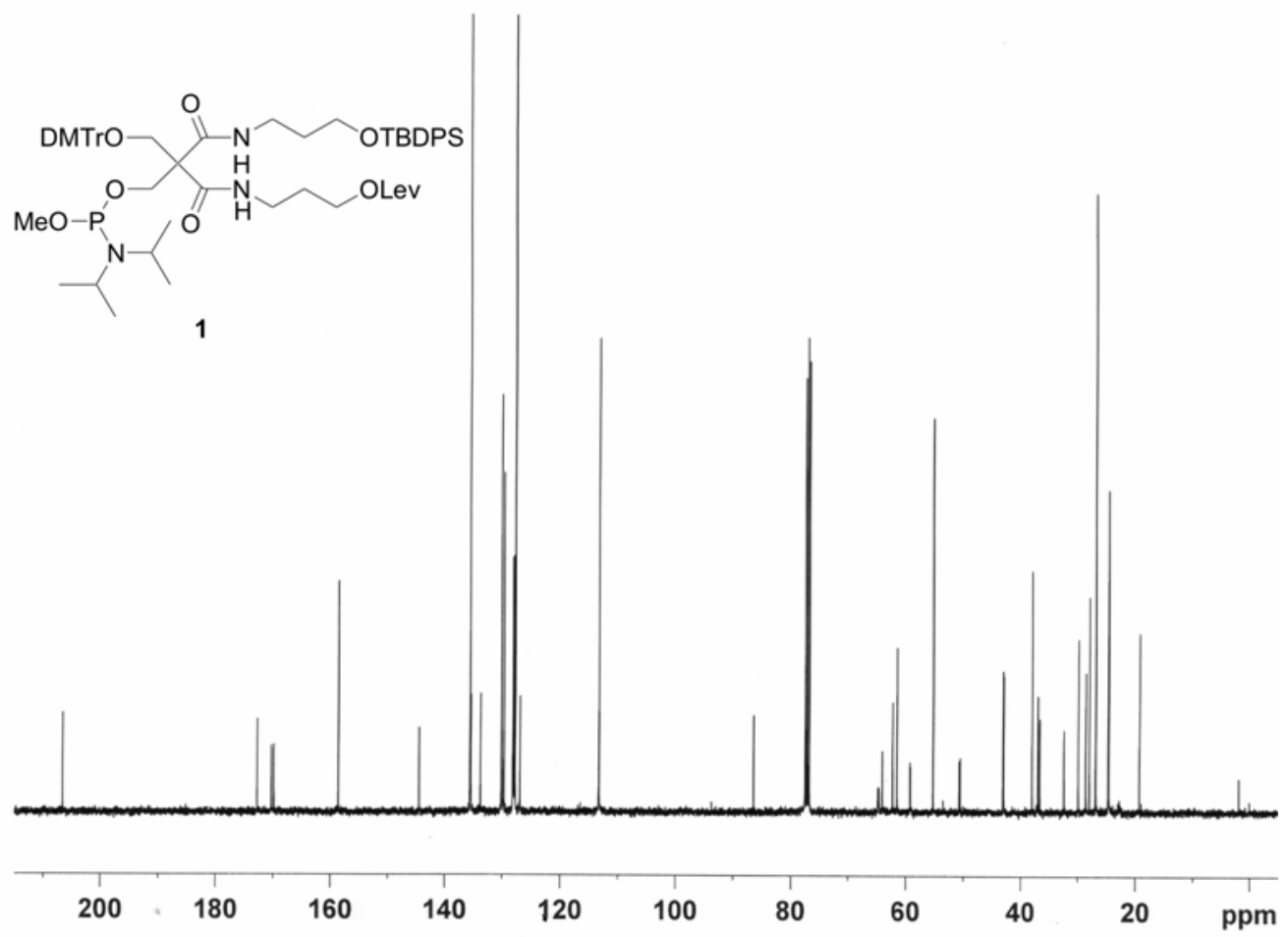

Figure S7. ${ }^{13} \mathrm{C}$ NMR spectrum of compound $\mathbf{1}$.

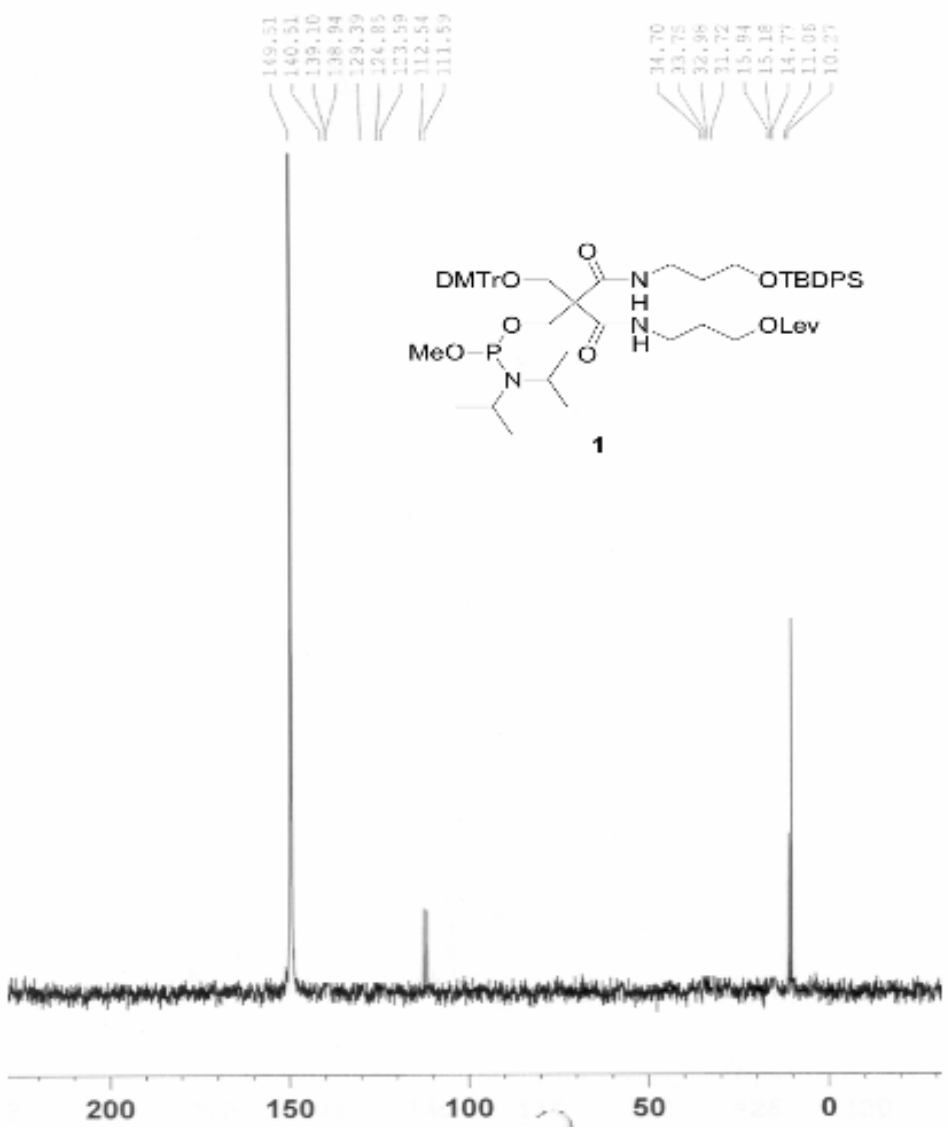

Figure S8. ${ }^{31} \mathrm{P}$ NMR spectrum of compound $\mathbf{1}$ 


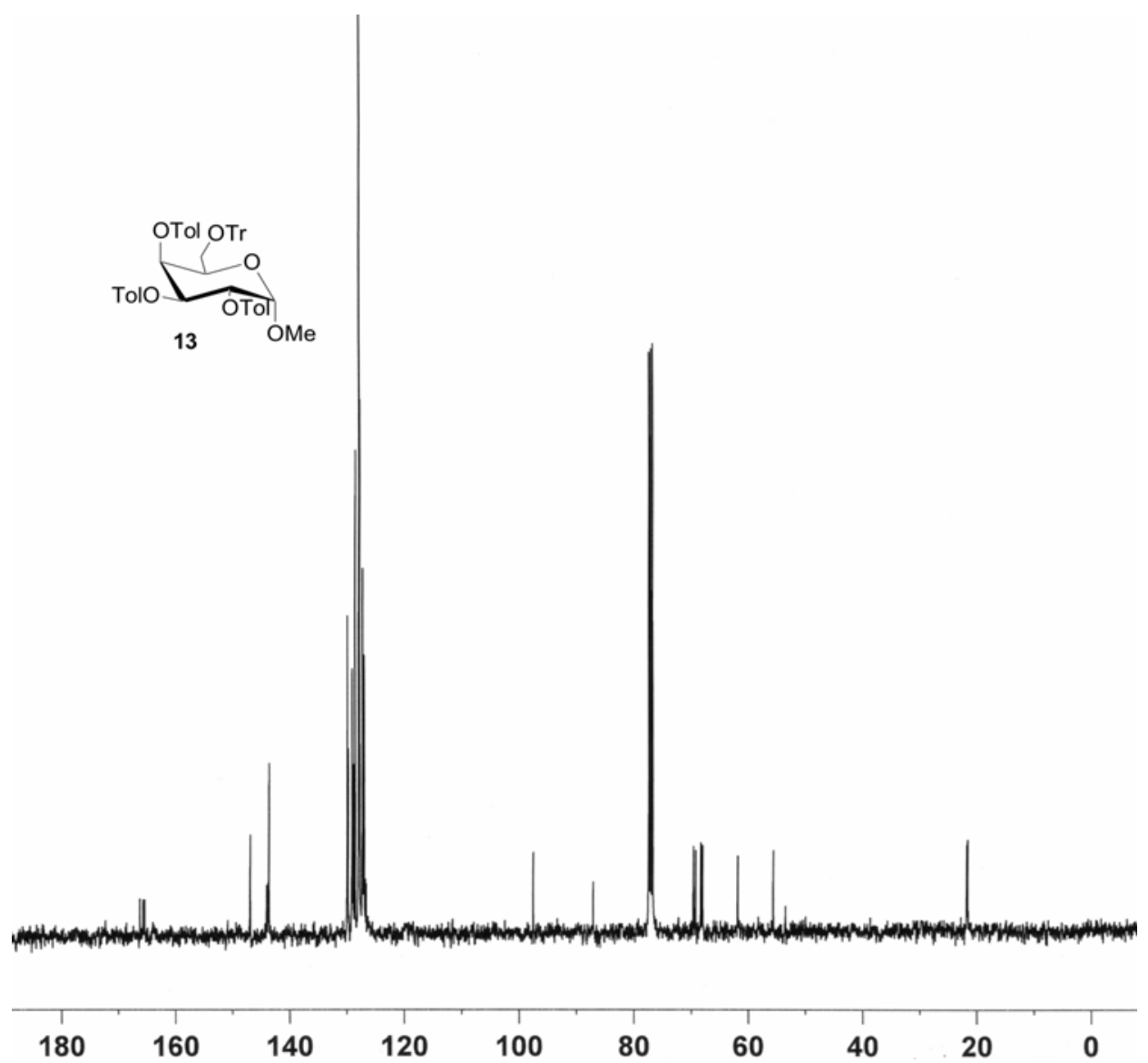

Figure S9. ${ }^{13} \mathrm{C}$ NMR spectrum of compound 13.

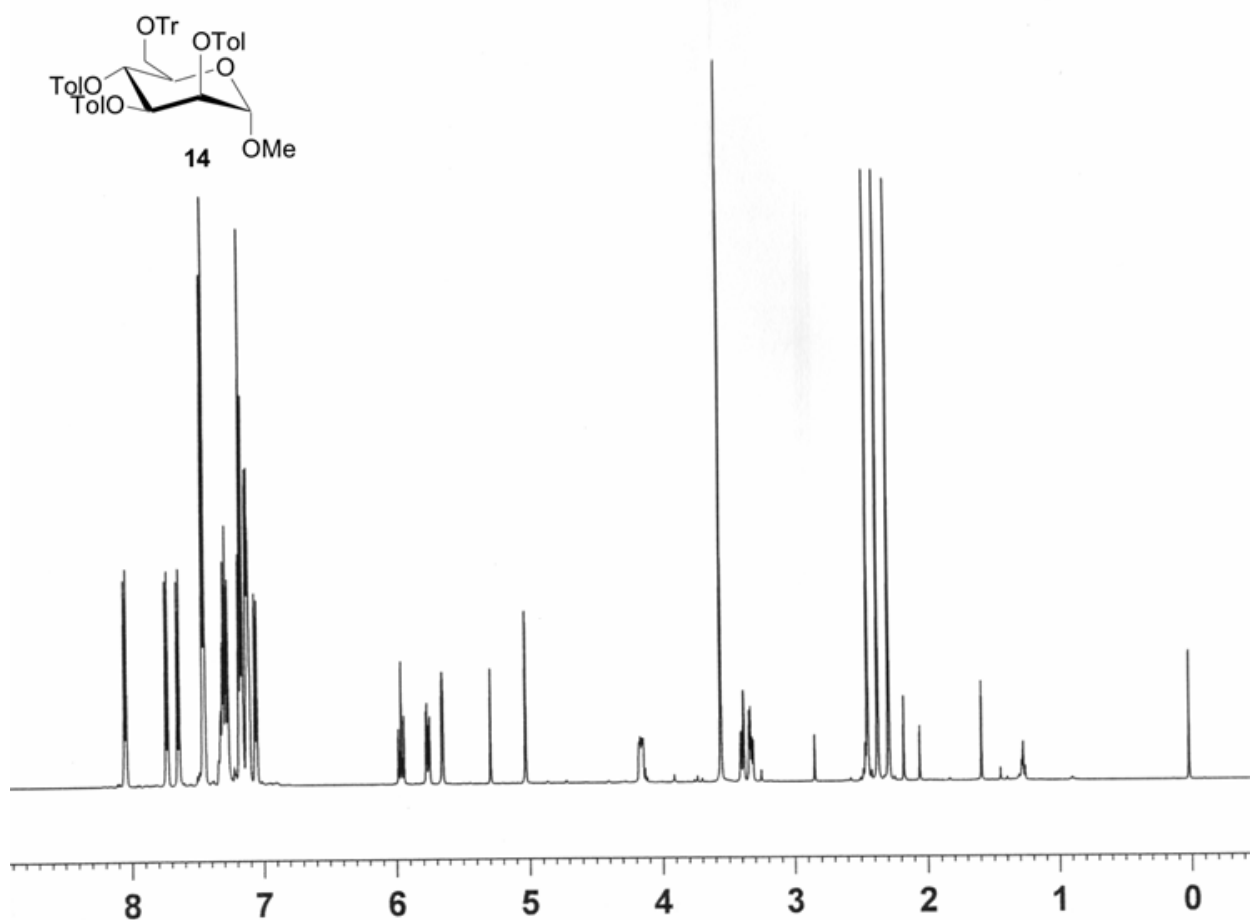

Figure S10. ${ }^{1}$ H NMR spectrum of compound 14. 


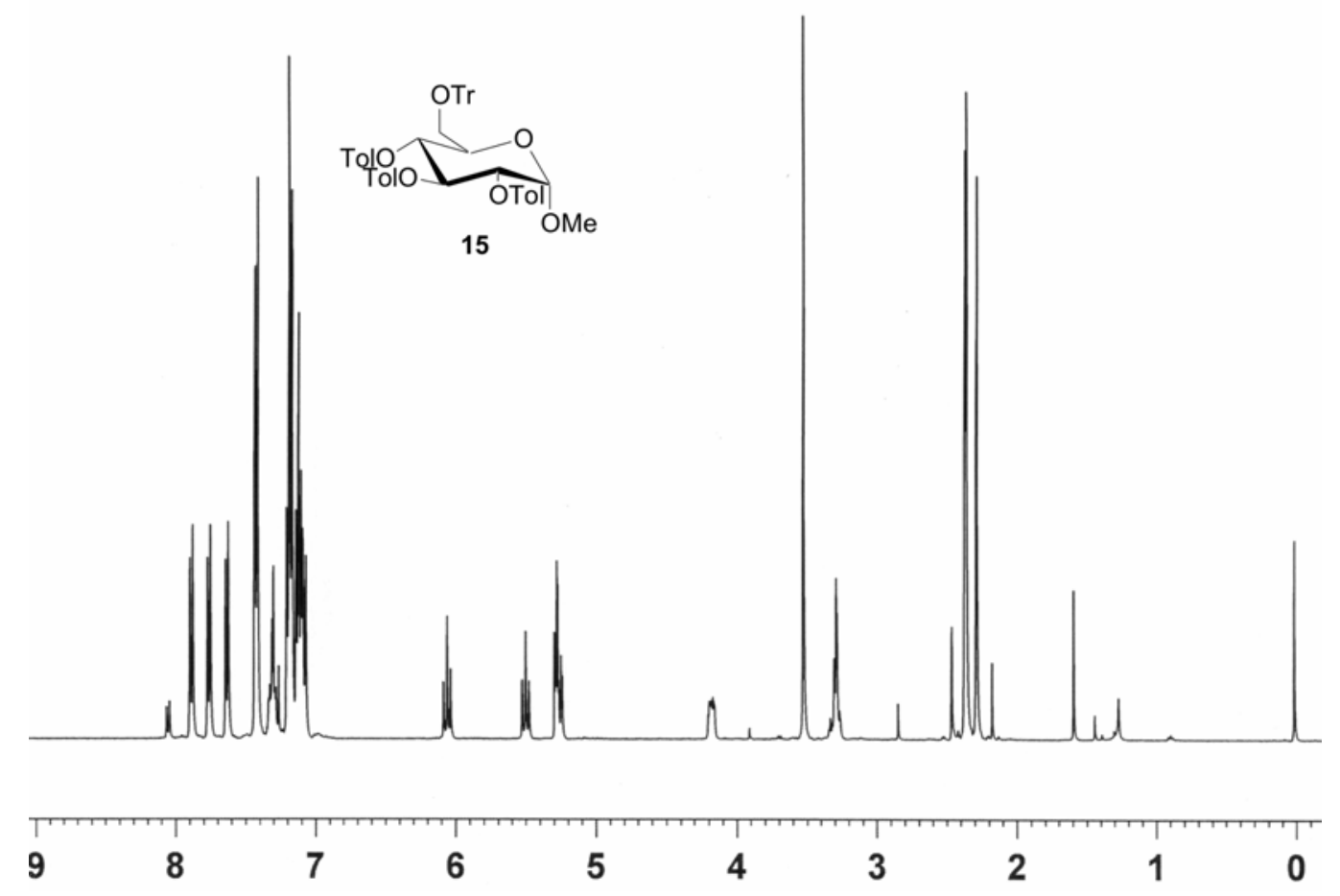

Figure S11. ${ }^{1} \mathrm{H}$ NMR spectrum of compound 15.

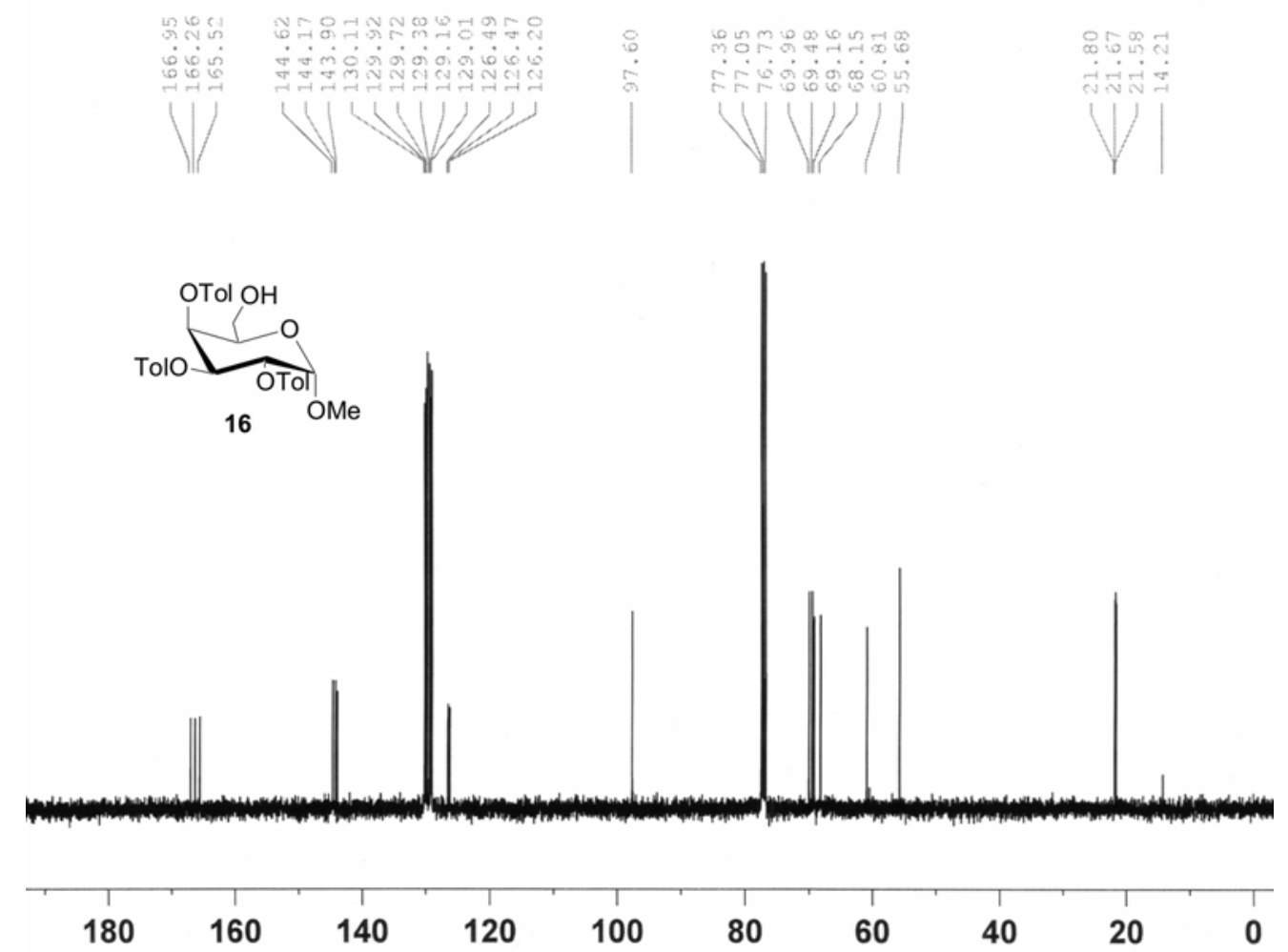

Figure S12. ${ }^{13} \mathrm{C}$ NMR spectrum of compound 16. 


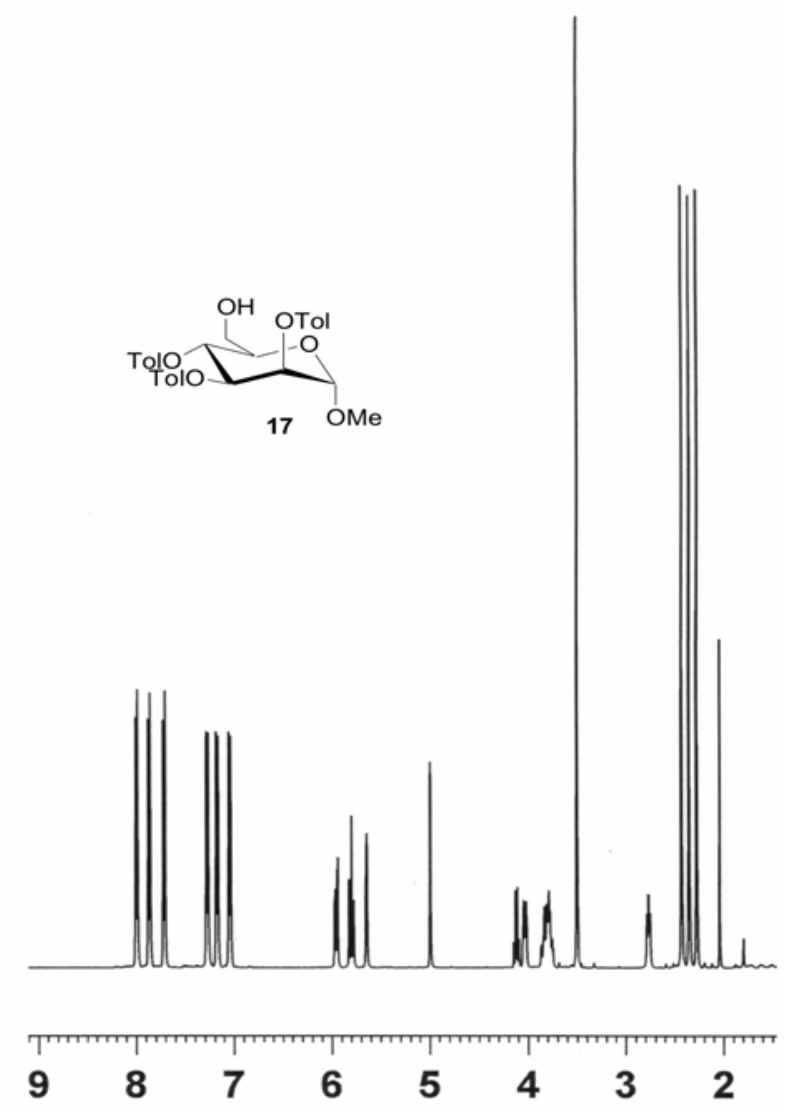

Figure S13. ${ }^{1} \mathrm{H}$ NMR spectrum of compound 17.

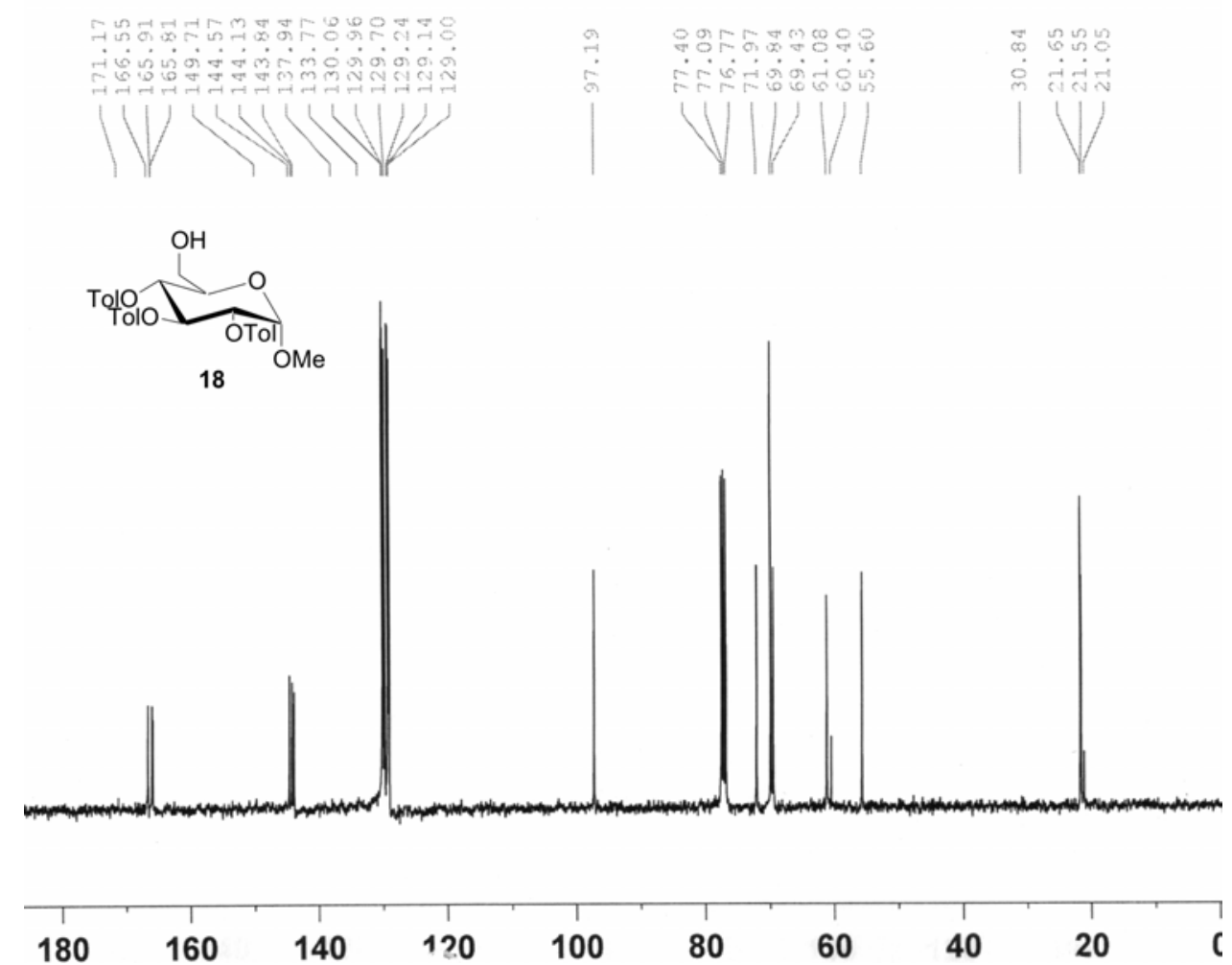

Figure S14. ${ }^{13} \mathrm{C}$ NMR spectrum of compound 18 . 

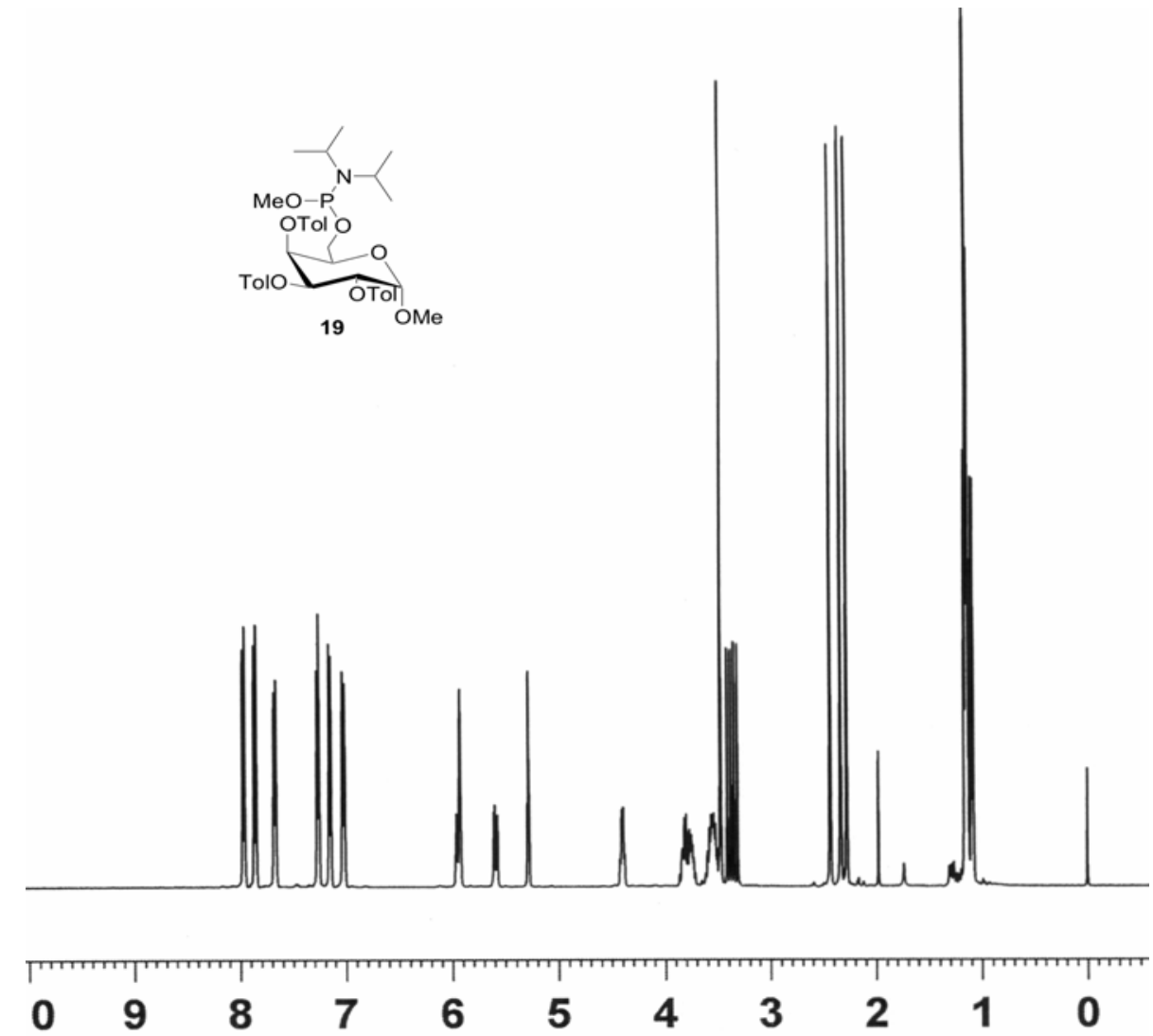

Figure S15. ${ }^{1} \mathrm{H}$ NMR spectrum of compound 19.

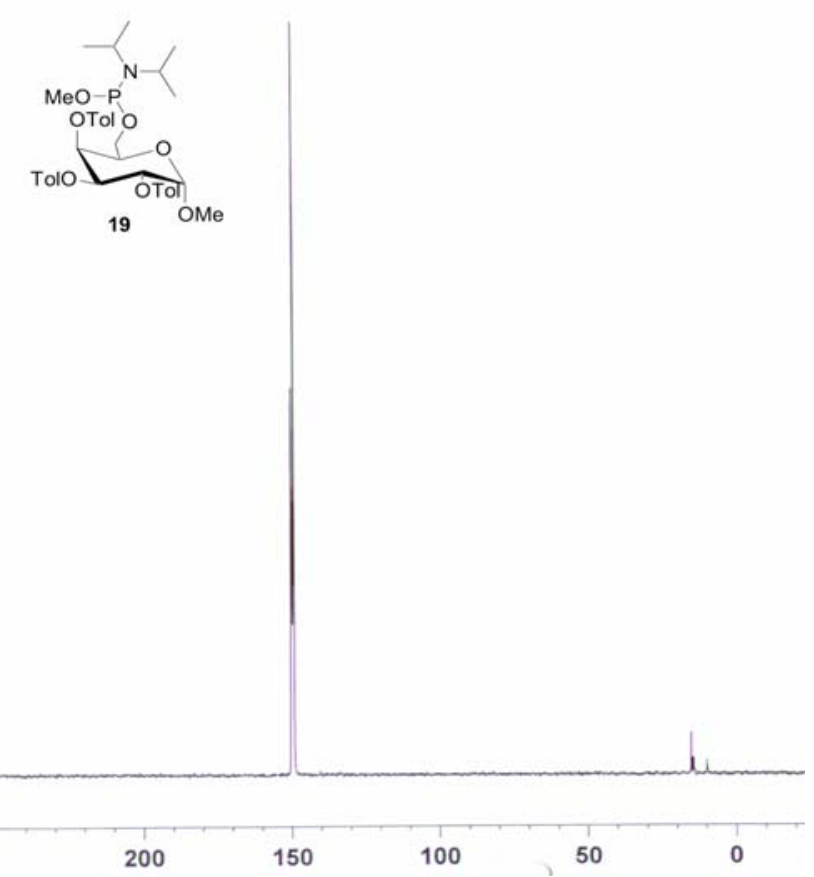

Figure S16. ${ }^{31} \mathrm{P}$ NMR spectrum of compound 19. 

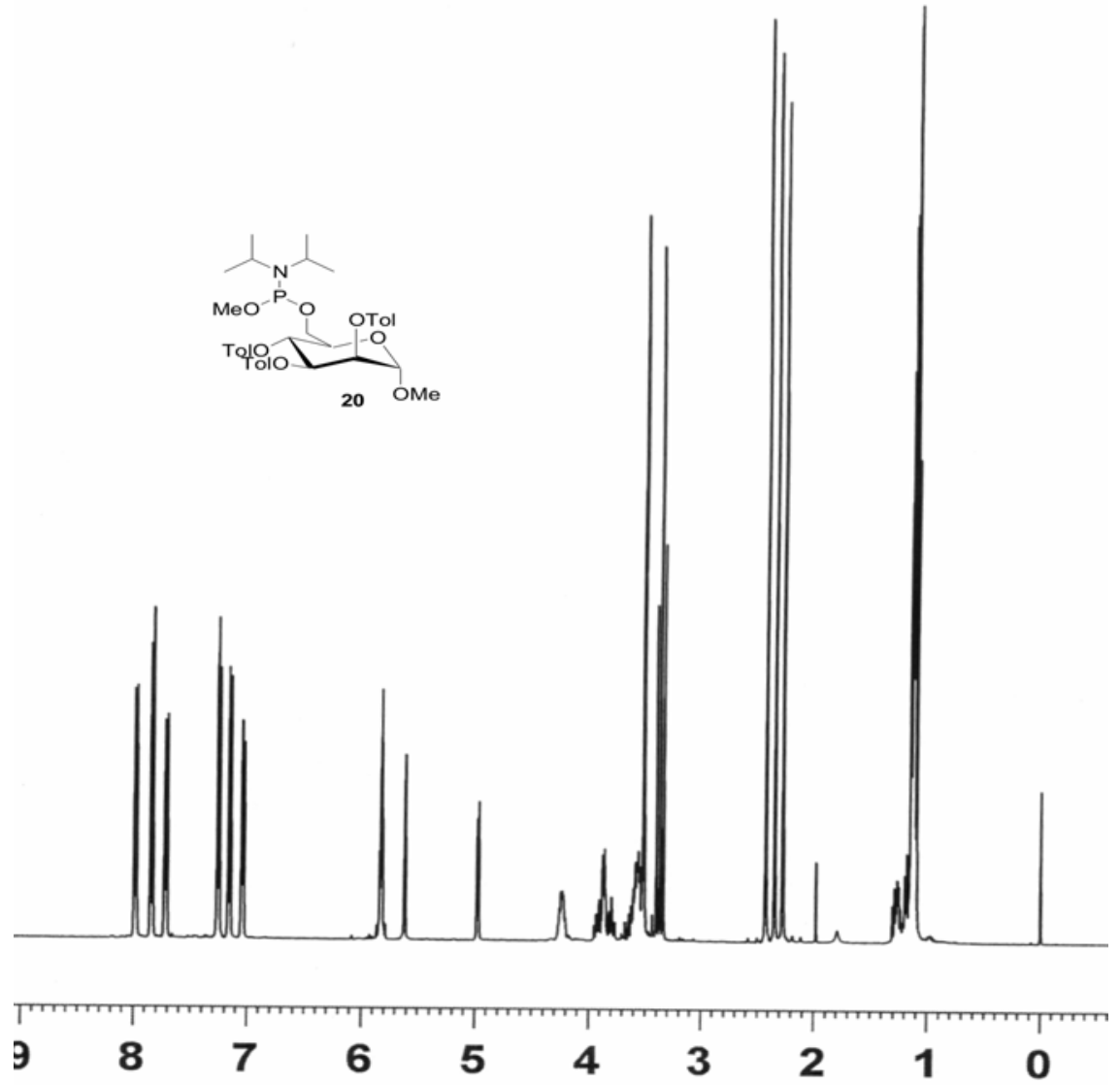

Figure S17. ${ }^{1} \mathrm{H}$ NMR spectrum of compound 20.

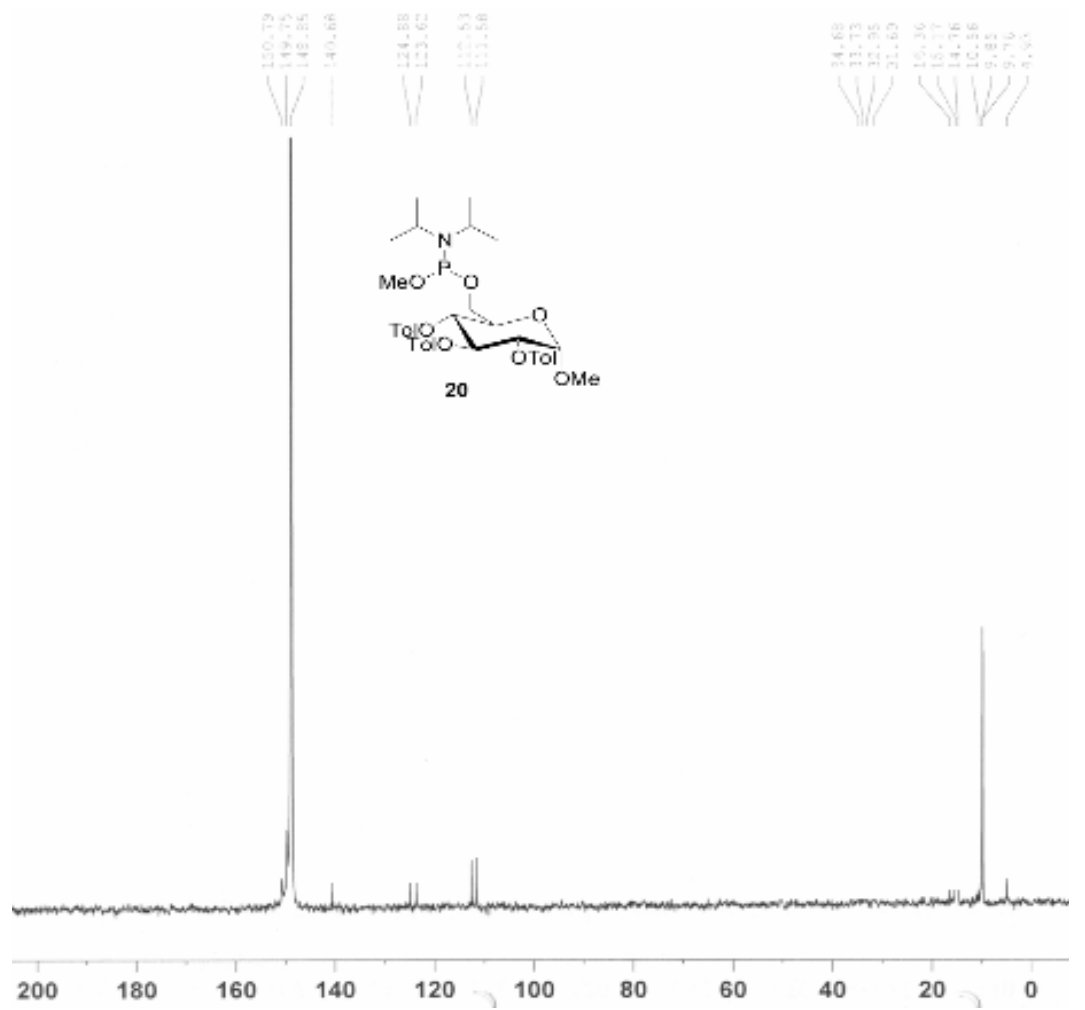

Figure S18. ${ }^{31} \mathrm{P}$ NMR spectrum of compound 20. 


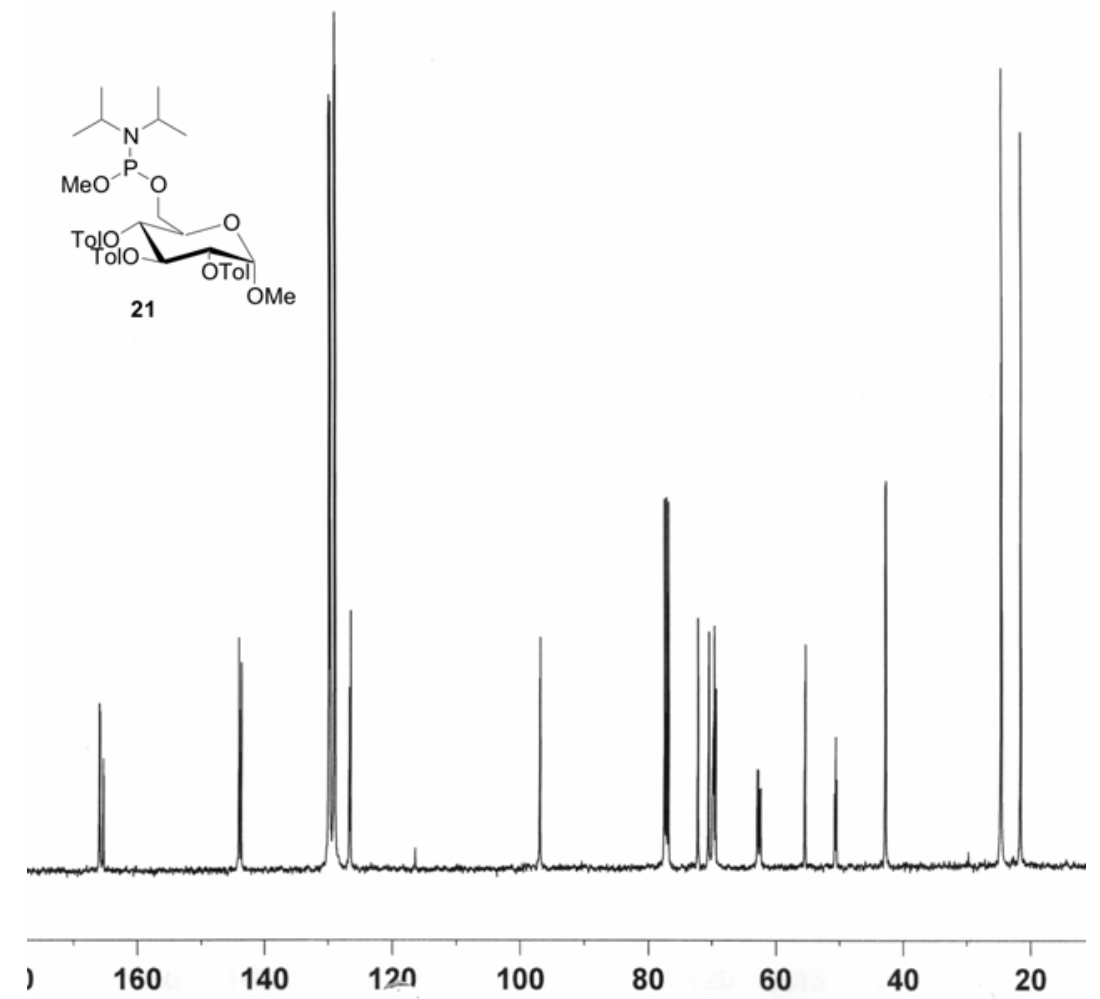

Figure S19. ${ }^{13} \mathrm{C}$ NMR spectrum of compound 21.

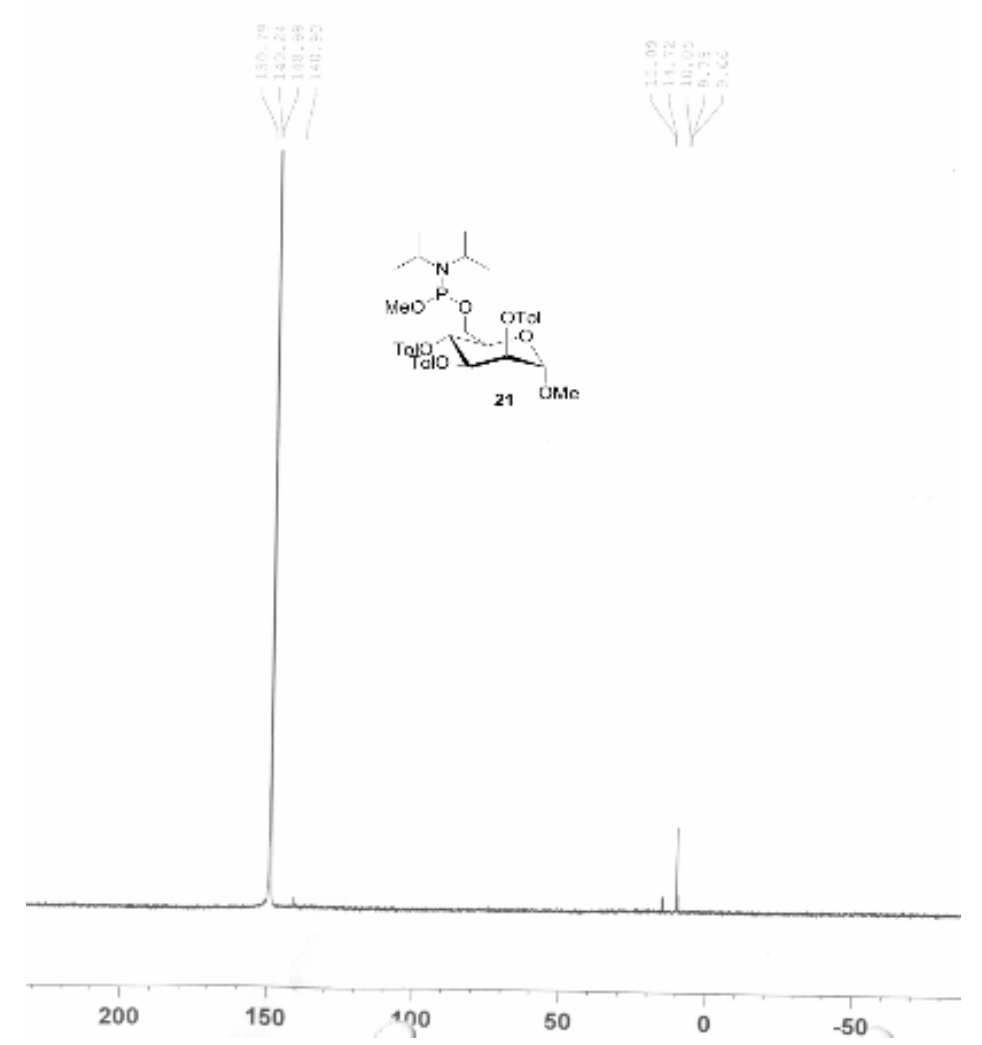

Figure S20. ${ }^{31} \mathrm{P}$ NMR spectrum of compound 21. 


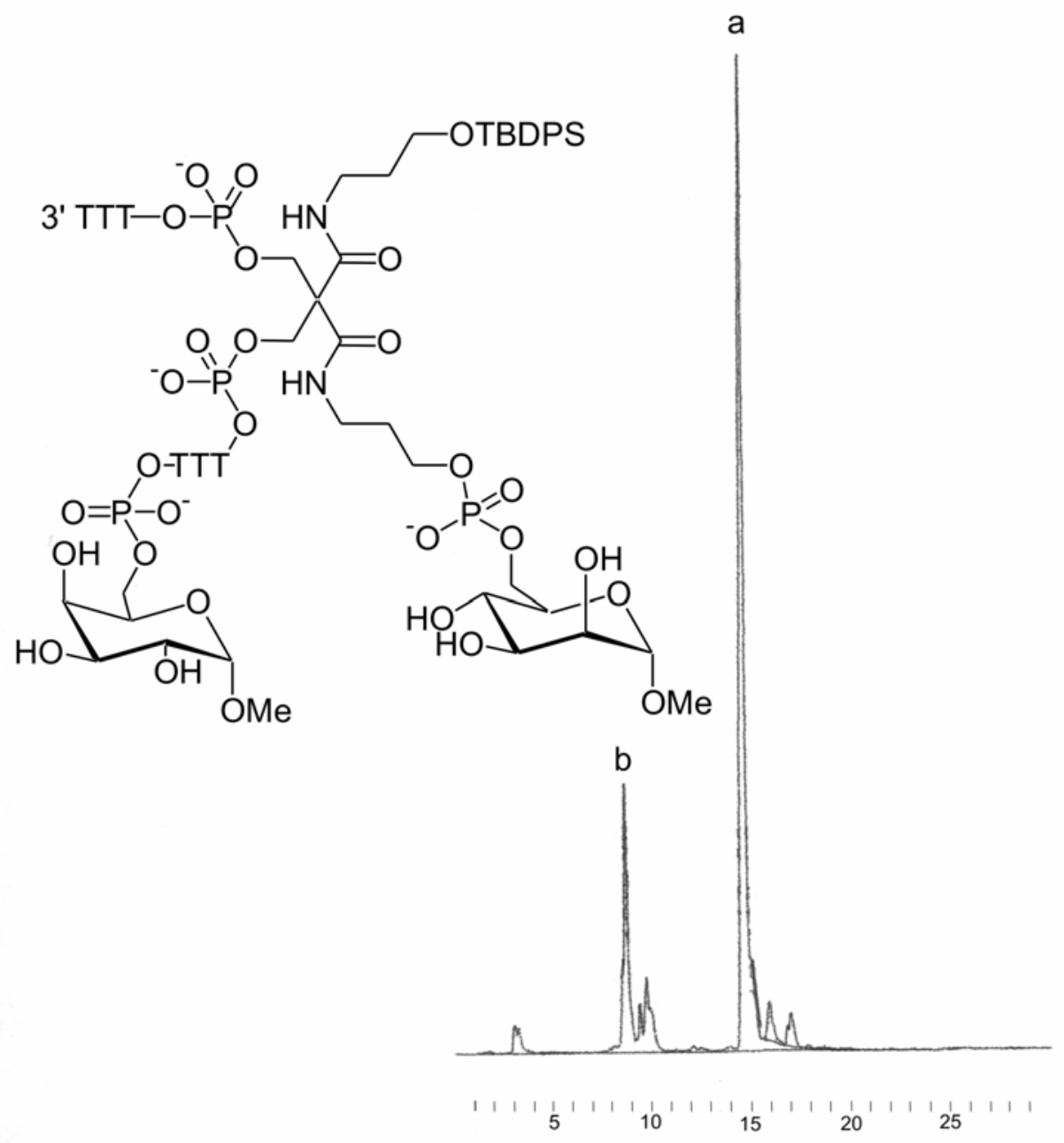

Figure S21. RP HPLC profile from of an oligonucleotide conjugate obtained after reaction with the second glycosyl phosphoramidite and subsequent ammonolytical release in solution at $260 \mathrm{~nm}$. Small part of the TBDPS protection was cleaved during the ammonolysis, and thus the product shows two peaks referring to the silylated $\left(a, t_{r}=14.5 \mathrm{~min}\right)$ and desilylated $\left(b, t_{r}=8.6\right.$ min) compounds. 


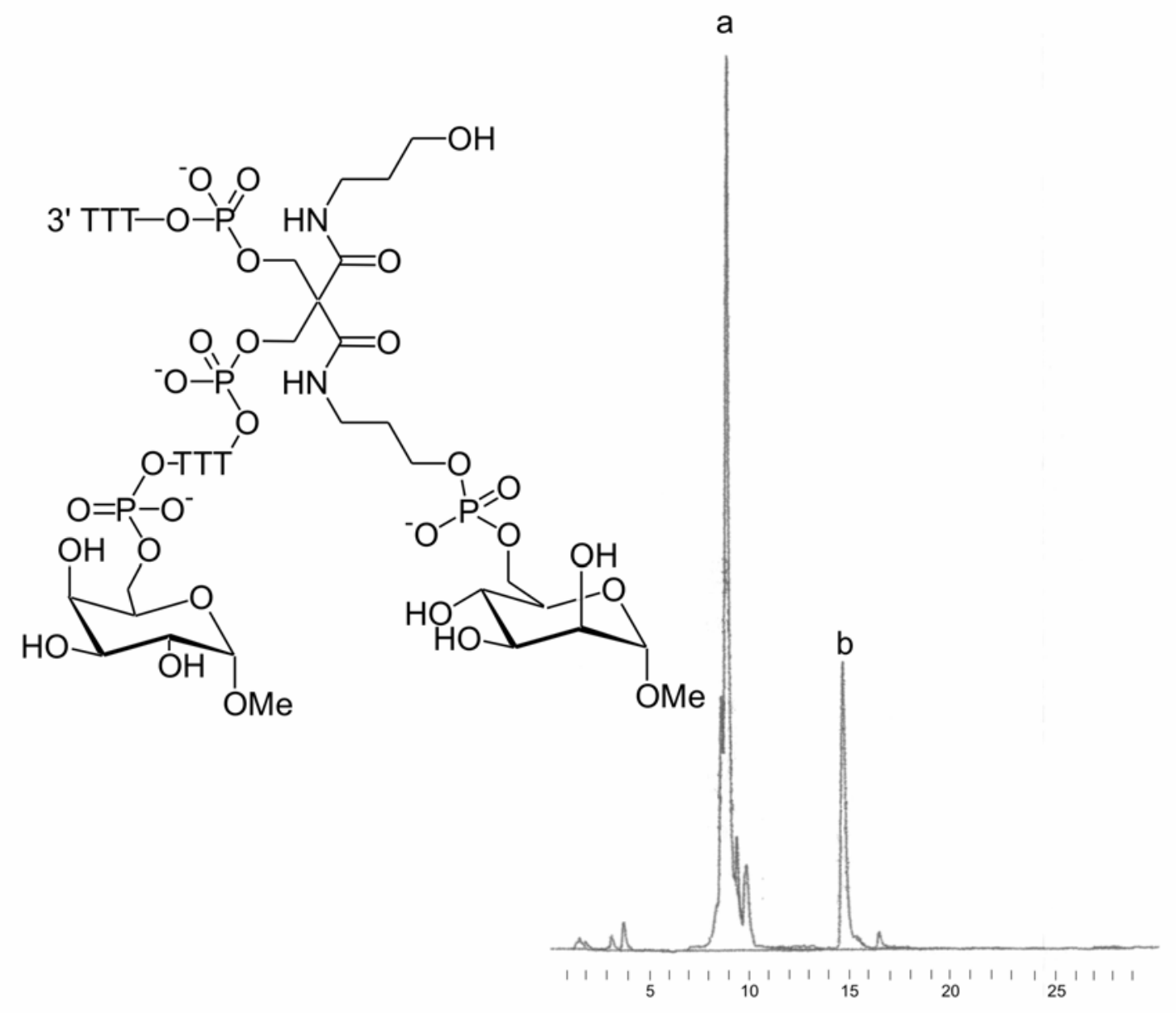

Figure S22. RP HPLC profile of the crude product mixture of an oligonucleotide conjugate obtained after TBDPS deprotection step and subsequent ammonolytical release in solution at 260 nm. Notation: (a) the desired product without TBPDS protection, $t_{r}=8.6 \mathrm{~min}$; (b) the starting material, $\mathrm{t}_{\mathrm{r}}=14.3 \mathrm{~min}$. 


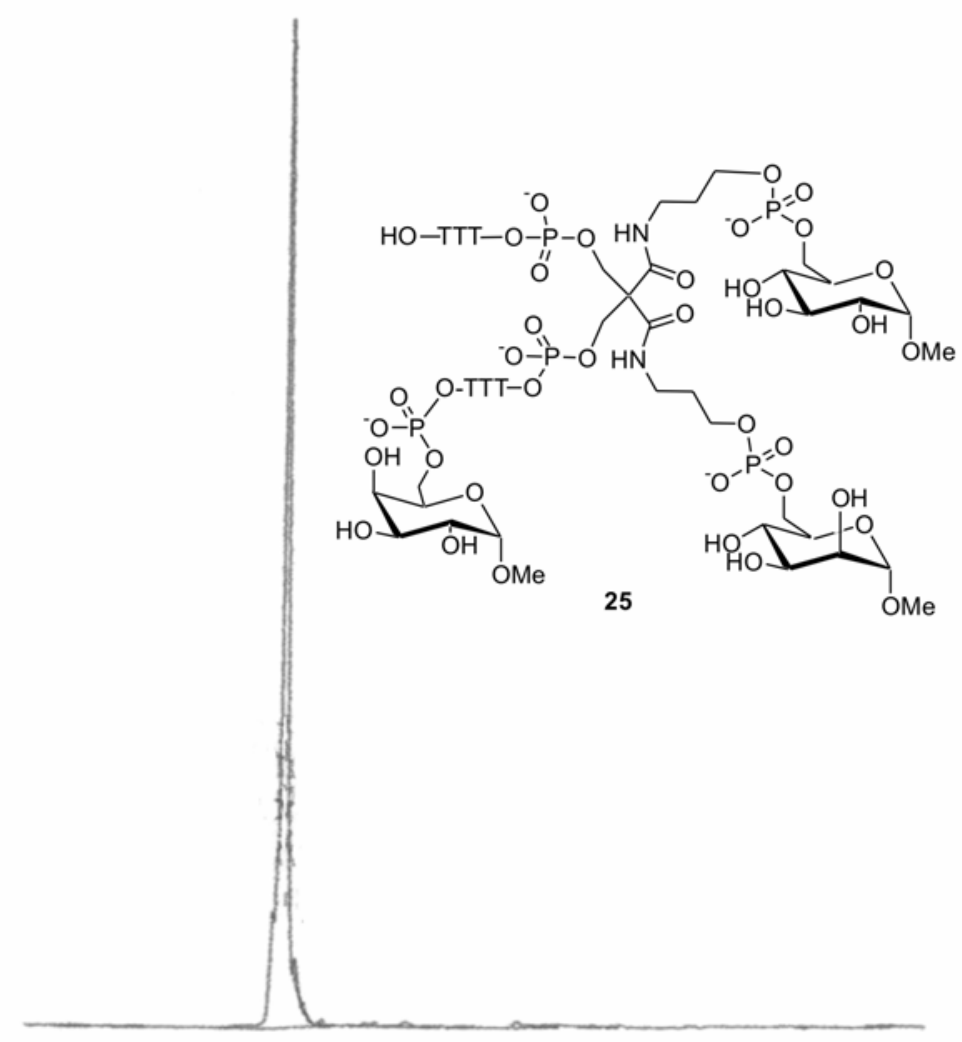

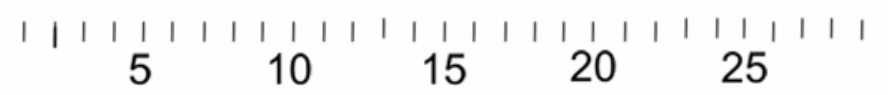

Figure S23. RP HPLC chromatogram of purified 25.

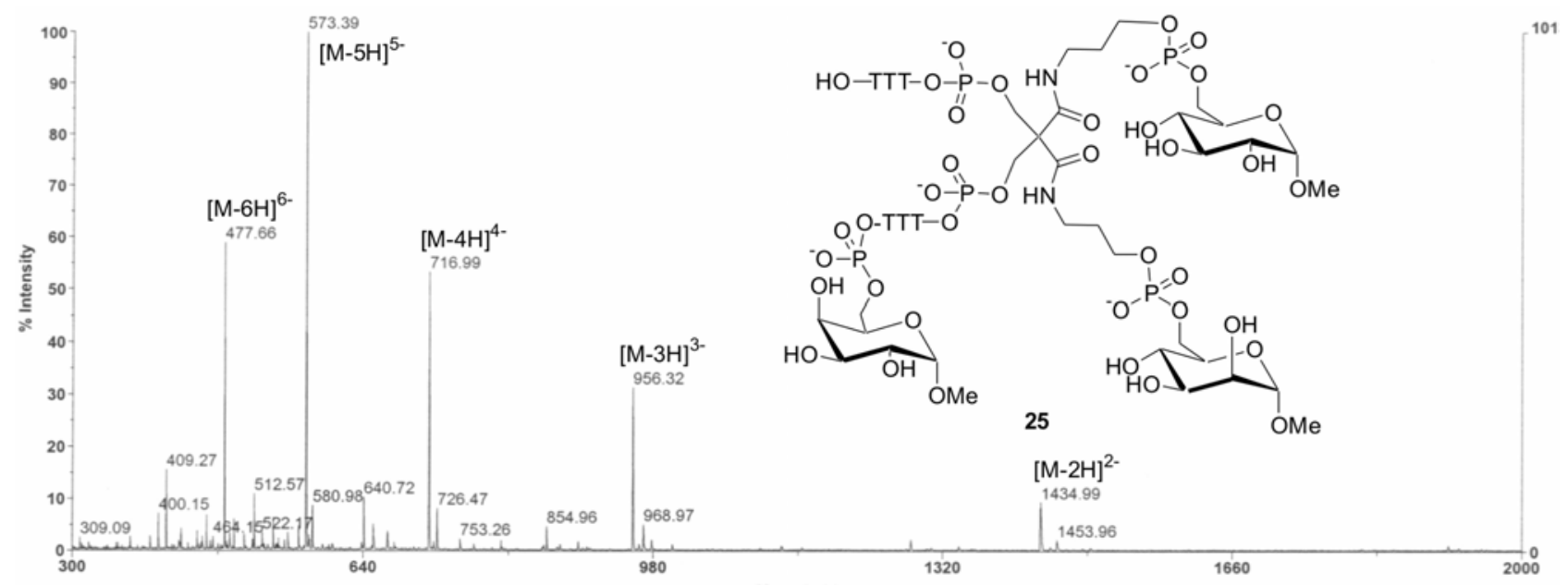

Figure S24. ESI-MS spectrum of compound 25. 


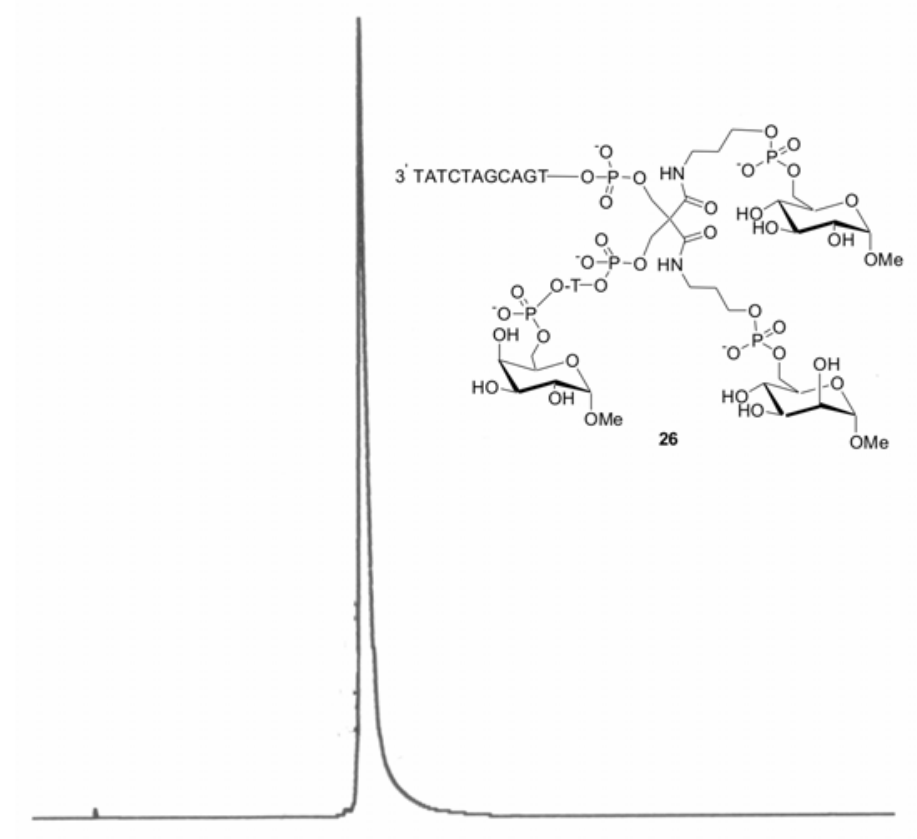

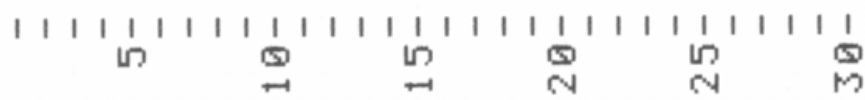

Figure S25. RP HPLC chromatogram of purified 26.

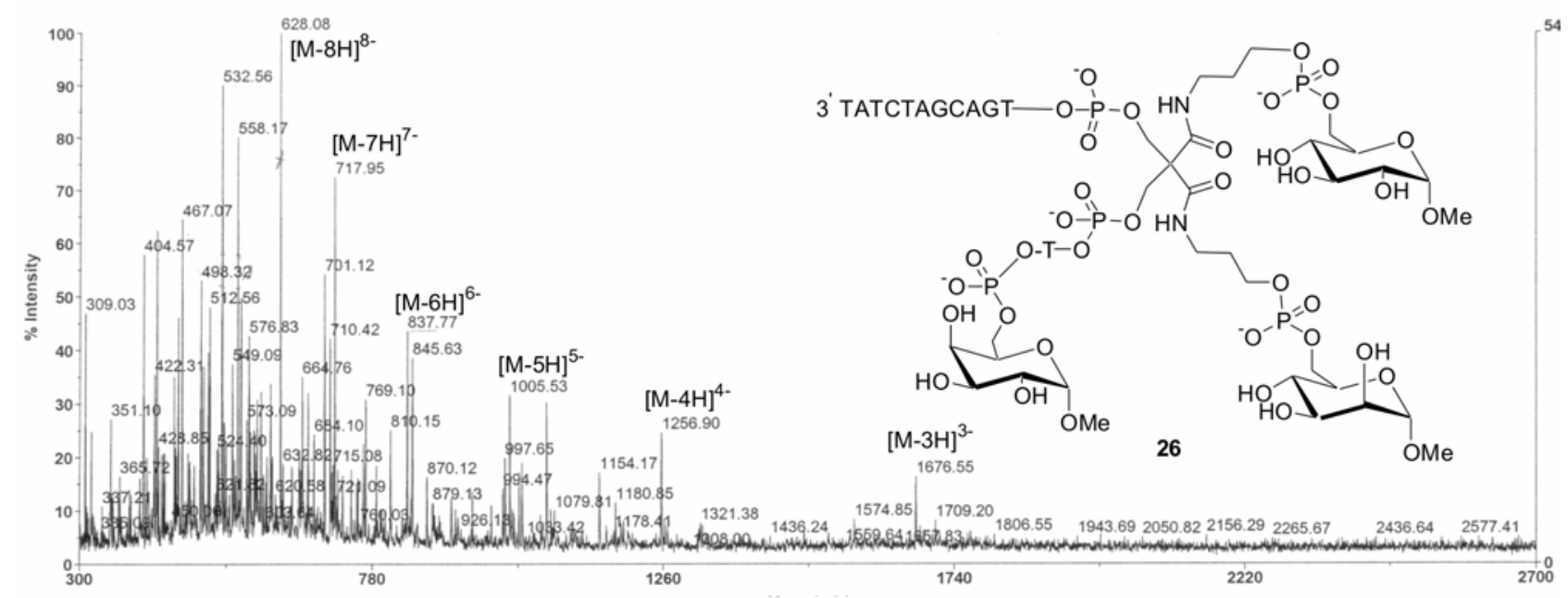

Figure S26. ESI-MS spectrum of compound 26. 